\title{
Large-Scale Fluorescence Calcium-Imaging Methods for Studies of Long-Term Memory in Behaving Mammals
}

\author{
Pablo Jercog ${ }^{1}$, Thomas Rogerson ${ }^{1}$, and Mark J. Schnitzer ${ }^{1,2,3}$ \\ ${ }^{1}$ CNC Program, Stanford University, Stanford, California 94305 \\ ${ }^{2}$ Howard Hughes Medical Institute, Stanford University, Stanford, California 94305 \\ ${ }^{3}$ James H. Clark Center for Biomedical Engineering \& Sciences, Stanford University, Stanford, \\ California 94305 \\ Correspondence: mschnitz@stanford.edu
}

During long-term memory formation, cellular and molecular processes reshape how individual neurons respond to specific patterns of synaptic input. It remains poorly understood how such changes impact information processing across networks of mammalian neurons. To observe how networks encode, store, and retrieve information, neuroscientists must track the dynamics of large ensembles of individual cells in behaving animals, over timescales commensurate with long-term memory. Fluorescence $\mathrm{Ca}^{2+}$-imaging techniques can monitor hundreds of neurons in behaving mice, opening exciting avenues for studies of learning and memory at the network level. Genetically encoded $\mathrm{Ca}^{2+}$ indicators allow neurons to be targeted by genetic type or connectivity. Chronic animal preparations permit repeated imaging of neural $\mathrm{Ca}^{2+}$ dynamics over multiple weeks. Together, these capabilities should enable unprecedented analyses of how ensemble neural codes evolve throughout memory processing and provide new insights into how memories are organized in the brain.

$\mathrm{R}_{\mathrm{b}}^{\mathrm{e}}$ ecent years have brought major new capabilities for manipulating mammalian neural circuits involved in memory processing. Advances in genetics, viral delivery methods, and optogenetic and pharmacogenetic techniques have allowed researchers to explore how specific cell types and neural projection pathways contribute to memory processing in behaving rodents (Ciocchi et al. 2010; Goshen et al. 2011; Letzkus et al. 2011; Garner et al. 2012; Liu et al. 2012; Nguyen-Vu et al. 2013; Cowansage et al. 2014; Redondo et al. 2014; Senn et al. 2014;
Wolff et al. 2014). By using optogenetic or pharmacogenetic modes of neural excitation in associative learning paradigms, one can substitute for conditioned (Choi et al. 2011; Kwon et al. 2014) or unconditioned (Johansen et al. 2010; Kimpo et al. 2014) stimuli, create synthetic memory traces (Garner et al. 2012), artificially evoke previously learned behaviors (Liu et al. 2012; Cowansage et al. 2014; Kim et al. 2014), and even condition mice to associate pairs of stimuli that were never actually presented together (Ramirez et al. 2013; Redondo et al.

Editors: Eric R. Kandel, Yadin Dudai, and Mark R. Mayford

Additional Perspectives on Learning and Memory available at www.cshperspectives.org

Copyright (C) 2016 Cold Spring Harbor Laboratory Press; all rights reserved; doi: 10.1101/cshperspect.a021824

Cite this article as Cold Spring Harb Perspect Biol 2016;8:a021824 
P. Jercog et al.

2014). One optogenetic study comparing the behavioral effects of fast neural inhibition against those of inactivation over longer timescales has also demonstrated that the set of brain circuits required for memory function depends strongly on the timescale at which one probes this necessity (Goshen et al. 2011), likely because slower methods of inactivation allow the brain to attain partial or total recoveries of function. Overall, recent advances in the causal manipulation of mammalian neural circuits have yielded important gains in the delineation of necessary and sufficient neural events for memory performance.

To complement the new approaches for perturbing circuits, neuroscientists also need improved observational methods for probing the neural representations the mammalian brain uses normally for memory processing and storage. In many cases, these representations appear to be distributed over large networks of cells and multiple brain areas (Tse et al. 2007; Goshen et al. 2011; Cowansage et al. 2014; Redondo et al. 2014). As computer scientists well appreciate, the manner in which information is represented in storage can have a major impact on the ease of retrieving information, encoding objects' attributes along with their identities, classifying and grouping items according to their characteristics, and associating items that have defined relationships such as in space or time (Date 2000). To understand how the brain accomplishes these feats, we need in vivo recording methods capable of revealing large-scale neural representations and tracking their evolution over timescales pertinent to long-term memory. Such methods would open the door to sophisticated studies of how large-scale neural dynamics and codes may facilitate or hinder different forms of information management in the mammalian brain (Sadtler et al. 2014).

Large-scale $\mathrm{Ca}^{2+}$-imaging techniques offer considerable promise toward achieving studies of this kind (Dombeck et al. 2010; Komiyama et al. 2010; Harvey et al. 2012; Huber et al. 2012; Ziv et al. 2013; Heys et al. 2014; Low et al. 2014; Modi et al. 2014; Peters et al. 2014; Rickgauer et al. 2014; Hamel et al. 2015). Key technical advantages include the capacity to monitor the dynamics of hundreds of cells concurrently, target specific neuron types for study based on their genetic identities or connectivity patterns, reliably track individual cells for many weeks in behaving animals, extract the signals of individual neurons nearly regardless of their activity rates, and visualize the anatomical organization of memory storage at the cellular scale. Optical methods for $\mathrm{Ca}^{2+}$ imaging also lend themselves naturally to combined usages with other optical methods (Prakash et al. 2012; Deisseroth and Schnitzer 2013; Jorgenson et al. 2015), such as optogenetics (Rickgauer et al. 2014; Szabo et al. 2014; Grosenick et al. 2015; Packer et al. 2015), fluorescent tagging of activated neurons (Reijmers et al. 2007; Liu et al. 2012; Guenthner et al. 2013; Kawashima et al. 2013; Ramirez et al. 2013; Redondo et al. 2014), and postmortem imaging of optically cleared tissues (Hama et al. 2011; Chung et al. 2013; Ke et al. 2013; Susaki et al. 2014; Yang et al. 2014a). In the future, integrated optical studies will likely combine observations of neurons' normal activity patterns, precise optogenetic manipulations of these dynamics, and detailed postmortem examinations of the dendritic morphologies, axonal projections, and macromolecular architectures of the very same cells (Deisseroth and Schnitzer 2013; Jorgenson et al. 2015).

This review aims to introduce in vivo $\mathrm{Ca}^{2+}$ imaging methods to researchers studying mammalian learning and memory. The next sections provide technical information for practitioners of in vivo $\mathrm{Ca}^{2+}$ imaging, emphasizing methodological strengths and limitations. Later sections discuss the types of experiments on learning and memory that $\mathrm{Ca}^{2+}$-imaging techniques are likely to enable in the near future.

\section{$\mathrm{Ca}^{2+}$ IMAGING AS A MEANS OF INFERRING NEURONAL SPIKING DYNAMICS}

Nearly all neuron types express voltage-sensitive $\mathrm{Ca}^{2+}$ channels (Trimmer and Rhodes 2004). Fluorescence $\mathrm{Ca}^{2+}$ imaging as a means of detecting somatic spiking dynamics relies on increases in intracellular $\mathrm{Ca}^{2+}$ ion concentration, $\left[\mathrm{Ca}^{2+}\right]$, which occur in response to neural membrane depolarization (Helmchen et al. 
1996; Grienberger and Konnerth 2012; Hamel et al. 2015). An essential part of all $\mathrm{Ca}^{2+}$-imaging methodologies is the $\mathrm{Ca}^{2+}$ indicator, a fluorescent reporter molecule that changes its photophysical properties in response to variations in intracellular $\left[\mathrm{Ca}^{2+}\right]$. The detailed biophysical processes underlying $\mathrm{Ca}^{2+}$ imaging have been reviewed at length elsewhere (Grienberger and Konnerth 2012). Thus, this section focuses more on the enabling features and pitfalls that memory researchers should consider when contemplating the use of a $\mathrm{Ca}^{2+}$ indicator as a means of visualizing spiking activity.

A fluorescent $\mathrm{Ca}^{2+}$ indicator molecule can bind one or more $\mathrm{Ca}^{2+}$ ions, which thereby alters the indicator's optical properties (Tian et al. 2009; Grienberger and Konnerth 2012). In general, there are distinct classes of indicators that undergo different types of photophysical changes, such as in fluorescence intensity, absorption or emission spectra, or emission lifetime (Grienberger and Konnerth 2012). For studies of long-term memory, researchers will generally want to choose a $\mathrm{Ca}^{2+}$ indicator that is genetically encoded (Mank et al. 2008; Grienberger and Konnerth 2012; Looger and Griesbeck 2012; Tian et al. 2012) owing to the capacity for stably expressing these protein sensors over time courses commensurate with those of long-term memory storage, such as for the types of experiments considered here in later sections.

For $\mathrm{Ca}^{2+}$-imaging studies in behaving mammals, the genetically encoded indicator that is most widely used at present (e.g., based on gene requests to Addgene) is GCaMP6, which can bind up to four $\mathrm{Ca}^{2+}$ ions and reports $\left[\mathrm{Ca}^{2+}\right]$ rises via increases in the intensity of its green fluorescence emissions (Chen et al. 2013). GCaMP6 has a greater dynamic range of fluorescence signaling than prior genetically encoded $\mathrm{Ca}^{2+}$ indicators. It also has $\mathrm{Ca}^{2+}$ binding kinetics rivaling those of the best synthetic $\mathrm{Ca}^{2+}$ indicators used for acute in vivo imaging studies (Garaschuk et al. 2006, Komiyama et al. 2010, Modi et al. 2014). Emerging types of genetically encoded red fluorescent $\mathrm{Ca}^{2+}$ indicators with spectrally distinct emissions from GCaMP6 open up interesting possibilities for monitoring the dynamics of two distinct cell types simultaneously (Inoue et al. 2015).

Despite the impressive capabilities of GCaMP6, no $\mathrm{Ca}^{2+}$ indicator provides an exact readout of membrane voltage dynamics (Fig. $1 \mathrm{~A}-\mathrm{H})$. The biophysical processes that govern the $\left[\mathrm{Ca}^{2+}\right]$ rise in response to an action potential include $\mathrm{Ca}^{2+}$ channel activation and intracellular $\mathrm{Ca}^{2+}$ buffering and are distinct from those setting the action potential's electrical waveform (Helmchen et al. 1996). The timedependence of the signals from a $\mathrm{Ca}^{2+}$ indicator also depends strongly on its $\mathrm{Ca}^{2+}$ handling properties, particularly the kinetic rates, equilibrium constant and Hill coefficient for $\mathrm{Ca}^{2+}$ binding and unbinding (Fig. 1A-D,G,H) (Sun et al. 2013). Hence, beyond the intrinsic differences between the dynamics of transmembrane voltage and intracellular $\mathrm{Ca}^{2+}$ excitation, the signals from a fluorescent $\mathrm{Ca}^{2+}$ indicator represent a temporally filtered version of the intracellular $\left[\mathrm{Ca}^{2+}\right]$ time course. Because of the experimental difficulty of directly relating a cell's time-varying fluorescence emissions to its intracellular $\left[\mathrm{Ca}^{2+}\right]$ dynamics in a live brain, virtually all researchers express fluorescence time traces from in vivo $\mathrm{Ca}^{2+}$-imaging studies in units of a percentage change from each cell's baseline fluorescence level, typically denoted $\Delta F(t) / F_{0}$.

There are three main variants of GCaMP6 (slow, medium, and fast) that have different $\mathrm{Ca}^{2+}$-binding kinetics and, hence, temporally filter intracellular $\left[\mathrm{Ca}^{2+}\right]$ dynamics to different degrees (Fig. 1) (Chen et al. 2013). The slow variant, GCaMP6s, binds $\mathrm{Ca}^{2+}$ more tightly than the fast variant, GCaMP6f. This difference confers greater $\mathrm{Ca}^{2+}$ sensitivity to GCaMP6s and leads to fluorescence transients of longer duration (Fig. 1C), but sacrifices signaling speed and the ability to distinguish action potentials occurring in quick succession (Fig. 1A,G,H). For GCaMP6s, the fluorescence signals in response to an action potential have a rise timeconstant of $\sim 180 \mathrm{msec}$ and a decay time constant of $\sim 580 \mathrm{msec}$, whereas, for GCaMP6f, these values are $\sim 30 \mathrm{msec}$ and $\sim 150 \mathrm{msec}$, respectively (Fig. 1G,H) (Chen et al. 2013). Cooperation and saturation effects in the binding of 
P. Jercog et al.

A
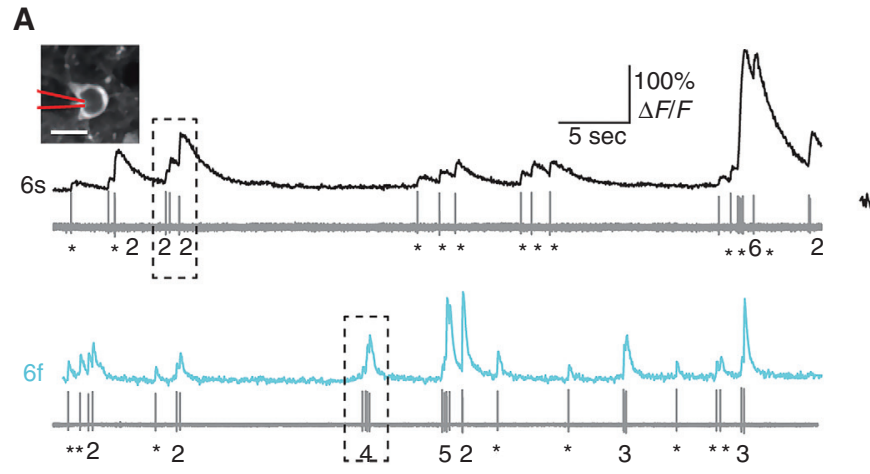

E
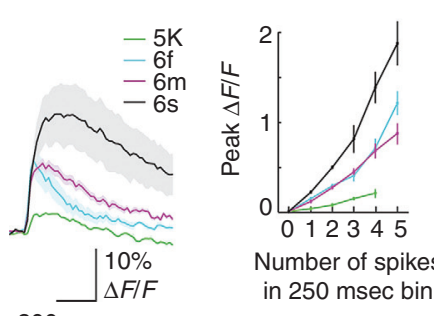

Number of spikes

in $250 \mathrm{msec}$ bin
F

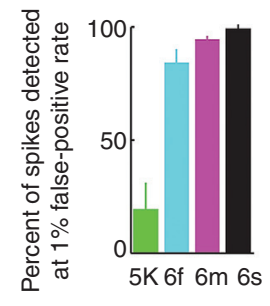

G
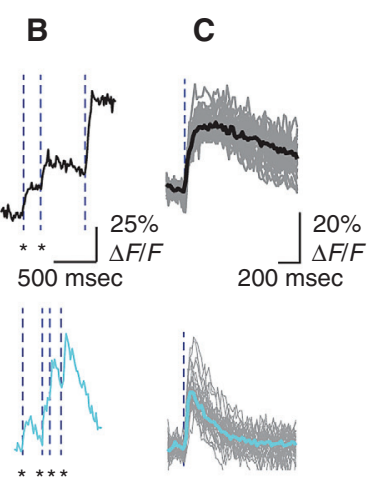

H
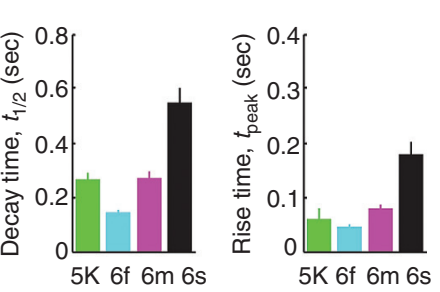

Figure 1. The GCaMP6 family of genetically encoded $\mathrm{Ca}^{2+}$ indicators allows high-fidelity detection of action potentials from neocortical pyramidal cells in live mice and $\sim 20-200 \mathrm{msec}$ spike timing estimation accuracy. (A) In pyramidal neurons expressing GCaMP6s (black traces) or GCaMP6f (cyan traces) in neocortical visual area $\mathrm{V} 1$ of live mice, simultaneous loose-seal cell-attached electrical and two-photon fluorescence $\mathrm{Ca}^{2+}$-imaging recordings show the reliability of the optical response to each action potential. Asterisks below the electrical traces (lower traces in each pair) mark occurrences of individual action potentials; numerals mark action potential bursts and report the number of spikes in each burst. (Inset) Two-photon image of a neuron expressing GCaMP6s; the recording pipette is indicated by the red lines. Scale bar, $10 \mu \mathrm{m}$. (B) Expanded view of the fluorescence traces in $A$ over the time periods delineated by the dashed boxes. Dashed vertical lines mark action potential occurrences. $(C)$ Fluorescence changes in response to one action potential for GCaMP6s (upper) and GCaMP6f (lower). Gray traces show the optical responses to individual spikes. Black and cyan traces show the average response. $(D)$ Traces of the median fluorescence change in response to one action potential for the genetically encoded $\mathrm{Ca}^{2+}$ indicators GCaMP5K (green trace), GCaMP6f (cyan), GCaMP6m (magenta), and GCaMP6s (black). Shading indicates S.E.M. (E) Peak fluorescence changes (mean \pm S.E.M.) observed by $\mathrm{Ca}^{2+}$ imaging as a function of the number of spikes detected electrically in a $250 \mathrm{msec}$ time bin during simultaneously acquired optical and electrical recordings in V1 neurons in live mice. Color key is the same as in $D$. $(F-H)$ Comparative performance metrics of the different indicators. (F) Percentage of action potentials correctly detected when the detection threshold is set to yield only $1 \%$ false positives. (G) Time constant for the decay of fluorescence following an action potential occurrence. $(\mathrm{H})$ Time constant for the fluorescence rise in response to an action potential. All error bars are s.E.M. All panels derived and modified from Chen et al. (2013).

multiple $\mathrm{Ca}^{2+}$ ions to a GCaMP6 molecule also cause nonlinearities in the temporal filtering.

In addition to these aspects of indicator dynamics, stochastic fluctuations in the emission and detection of fluorescence photons constrain the fidelity of action potential detection and the accuracy of spike-timing estimation (Wilt et al. 2013; Hamel et al. 2015). Photon "shot noise" has its origins in quantum mechanics and sets physical limits on spike detection fidelity and timing accuracy-even when additional noise sources, such as instrumentation noise, are minuscule. Signal detection and estimation theories provide theoretical lower bounds on the spike detection and timing errors incurred because of fluctuations 
in photon counts (Wilt et al. 2013; Hamel et al. 2015).

Because of these biophysical and optical facets of $\mathrm{Ca}^{2+}$ imaging, there is substantial variability in the relationship between the amplitude and waveform of a somatic $\mathrm{Ca}^{2+}$ transient, as seen by fluorescence imaging, and the number of action potentials underlying the transient (Fig. 1C). Moreover, the relationship between membrane voltage and somatic $\left[\mathrm{Ca}^{2+}\right]$ dynamics differs between different types of neurons. Cell types vary regarding the expression and properties of their $\mathrm{Ca}^{2+}$ channels, levels of intracellular $\left[\mathrm{Ca}^{2+}\right]$ buffering, and other aspects of $\mathrm{Ca}^{2+}$ signaling such as $\mathrm{Ca}^{2+}$-induced $\mathrm{Ca}^{2+}$ release from intracellular stores. Whenever feasible, it is best to empirically determine the relationship between $\mathrm{Ca}^{2+}$-related fluorescence signals and the underlying spike trains in the specific cell type of interest. A common approach is to perform simultaneous electrical recordings and fluorescence measurements in the exact same cells, such as in a brain slice (Tian et al. 2009), or by using in vivo $\mathrm{Ca}^{2+}$ imaging to guide the targeting of an electrode to a selected cell in a live animal (Fig. 1) (Chen et al. 2013).

Simultaneous optical and electrical recordings from visual cortical pyramidal neurons in live mice have revealed approximately linear relationships between the peak amplitude of a somatic $\mathrm{Ca}^{2+}$ transient and the underlying number of action potentials (Fig. 1E) (Chen et al. 2013). Other types of pyramidal cells likely also exhibit similar linear relationships between these parameters, but not necessarily with the same linear function. More generally, in neurons with temporally sparse spiking patterns, in vivo $\mathrm{Ca}^{2+}$ imaging usually reveals discrete $\mathrm{Ca}^{2+}$ transients representing one or more spikes.

Inhibitory interneurons have distinct $\mathrm{Ca}^{2+}$ signaling and buffering attributes from those of excitatory neurons, and they often fire spikes at fast rates or in bursts. In such fast-spiking neurons, it is typically infeasible to assign precise spike numbers to individual $\mathrm{Ca}^{2+}$ transients. Still, $\mathrm{Ca}^{2+}$ imaging generally reveals the overall patterns of how interneurons modulate their time-dependent activity rates; for instance, re- cent $\mathrm{Ca}^{2+}$-imaging studies of visual cortical interneurons have monitored visually evoked increases in somatic fluorescence intensity, rather than incidences of individual $\mathrm{Ca}^{2+}$ transients (Kerlin et al. 2010; Runyan et al. 2010; El-Boustani and Sur 2014).

Regardless of cell type, in live or behaving animals, there are yet additional noise sources that can make it challenging to infer the exact number of spikes underlying any $\mathrm{Ca}^{2+}$ transient. These noise sources are generally nonstationary over time and can originate from hemodynamic events, brain motion artifacts induced by physiological rhythms or voluntary movements, or fluorescence $\mathrm{Ca}^{2+}$ signals from neuropil activation. Notwithstanding, there is almost always a useful, monotonic relationship between the mean intensity of somatic fluorescence emissions from a $\mathrm{Ca}^{2+}$ indicator and the rate of somatic spiking.

In vivo $\mathrm{Ca}^{2+}$ imaging generally does not reliably reveal membrane hyperpolarization or other subthreshold aspects of somatic voltage dynamics. However, outside the soma, by sparsely expressing a $\mathrm{Ca}^{2+}$ indicator in isolated cells, one can detect in vivo the subcellular $\mathrm{Ca}^{2+}$ activation patterns of individual dendrites, dendritic spines, and even axons (Bock et al. 2011; Petreanu et al. 2012; Xu et al. 2012; Chen et al. 2013; Glickfeld et al. 2013; Kaifosh et al. 2013; Lovett-Barron et al. 2014; Sheffield and Dombeck 2015).

Overall, although in vivo $\mathrm{Ca}^{2+}$ imaging may not be able to adjudicate issues that hinge on exact spike counts and millisecond-scale timing, there are many questions about neural coding and memory processing that $\mathrm{Ca}^{2+}$ imaging can answer. The latter questions might focus on the identities of cells that encode specific types of information, the acquisition and long-term stability of coding properties under different behavioral conditions, the relationships between coding properties and other cellular attributes, the extent to which ensembles of neurons encode information in a cooperative manner, how neural codes change across different brain states, or the anatomical relationships between cells involved in storing specific memories. 
P. Jercog et al.

\section{TARGETING SPECIFIC SUBSETS OF CELLS FOR EXPRESSION OF A GENETICALLY ENCODED $\mathrm{Ca}^{2+}$ INDICATOR}

To study large-scale neural coding by $\mathrm{Ca}^{2+}$ imaging, it is important to consider the various ways in which one can express a genetically encoded indicator in the cells of interest. To date, most $\mathrm{Ca}^{2+}$-imaging studies in behaving mammals based on a genetically encoded $\mathrm{Ca}^{2+}$ indicator have used an adeno-associated viral (AAV) vector to target indicator expression to specific neuron types at the virus injection site (Dombeck et al. 2010; Komiyama et al. 2010; Harvey et al. 2012; Huber et al. 2012; Ziv et al. 2013). A key consideration with the use of an AAV concerns the viral serotype, because distinct serotypes of AAV enter different neuron types to varying degrees (Aschauer et al. 2013). Another key factor is the genetic promoter used to express the $\mathrm{Ca}^{2+}$ indicator. For instance, an AAV whose genome incorporates a CaMK2a promoter can target indicator expression to the specific subset of virally infected neurons in which this promoter is active, such as pyramidal neurons (Ziv et al. 2013). A pan-neuronal promoter, such as the Synapsin promoter, drives expression in nearly all neuron types (Dombeck et al. 2010; Huber et al. 2012). However, many promoters of interest are too large to be packaged within an AAV. There are other viruses capable of delivering larger genetic payloads, but they tend to be either toxic to neurons or less effective at expressing a fluorescent indicator at the levels needed for adequate brightness.

Thus, a widely used alternate means of targeting specific cell types is to create an AAV that selectively drives indicator expression over the long-term in cells expressing the enzyme Crerecombinase (Sauer 1998). Many different Credriver mouse lines, transgenic animals that express this enzyme in particular classes of cells, are widely available (Madisen et al. 2010, 2015). Hence, a single viral construct that expresses the $\mathrm{Ca}^{2+}$ indicator in a Cre-dependent manner can be fruitfully combined with a wide variety of Cre-driver lines. This modular approach is generally more efficient and feasible than creating a separate virus for each cell type of interest.
In addition to facilitating studies of somatic $\mathrm{Ca}^{2+}$ activity, AAV-based strategies for GCaMP expression have enabled observations of $\mathrm{Ca}^{2+}$ activity in specific neural pathways, by imaging the $\mathrm{Ca}^{2+}$ dynamics of axons of neurons whose cell bodies lie elsewhere (e.g., in a brain area distal to the imaging field of view). This approach selectively confines the $\mathrm{Ca}^{2+}$ signals to neurons that have their cell bodies at the viral injection site and project axons to the imaging site (Petreanu et al. 2012; Xu et al. 2012; Glickfeld et al. 2013; Kaifosh et al. 2013; Lovett-Barron et al. 2014). For example, in higher visual areas of the mouse neocortex, this approach allowed selective imaging of axons from neurons with cell bodies in visual area V1 (Glickfeld et al. 2013). A promising alternative to this approach for imaging pathway specific $\mathrm{Ca}^{2+}$ activity is to use canine adenovirus-2 (CAV-2), which efficiently infects neuronal axons (Hnasko et al. 2006; Bru et al. 2010; Boender et al. 2014).

Other emerging strategies for expressing a genetically encoded $\mathrm{Ca}^{2+}$ indicator include the use of transgenic mice (Chen et al. 2012b; Zariwala et al. 2012; Dana et al. 2014; Madisen et al. 2015) or transsynaptic viruses (Osakada et al. 2011). Until recently, transgenic mice created to express genetically encoded $\mathrm{Ca}^{2+}$ indicators usually suffered from dimmer fluorescence levels than those attainable by viral delivery methods. This is because transgenic mice typically had one, or only a few, copies of the $\mathrm{Ca}^{2+}$ indicator gene. By comparison, many AAV particles can enter an individual infected cell, which boosts each cell's expression of the protein fluorophore. This issue is now widely appreciated, and a promising transgenic mouse strategy that uses a triple transgene approach to increase $\mathrm{Ca}^{2+}$ indicator expression levels has recently emerged (Madisen et al. 2015).

Transsynaptic neurotropic viruses that traverse neuronal synapses also offer interesting prospects for targeting $\mathrm{Ca}^{2+}$-imaging studies to cells receiving or providing specific synaptic inputs. Retrograde transsynaptic viruses include rabies (Kelly and Strick 2000; Taber et al. 2005; Wickersham et al. 2007a,b; Miyamichi et al. 2011; Osakada et al. 2011; Osakada and Callaway 2013) and pseudorabies (Enquist et al. 2002; 
Card et al. 2011; Card and Enquist 2014; Oyibo et al. 2014). The use of these viruses for anatomical mapping studies is established but applications to $\mathrm{Ca}^{2+}$ imaging remain somewhat experimental (Osakada et al. 2011). A key advantage of rabies has been that genetically modified versions of rabies exist that can pass retrograde across a single synapse, but not across disynaptic or polysynaptic projections (Etessami et al. 2000; Wickersham et al. 2007a,b). This restriction confines the set of cells under study to those with well-defined monosynaptic connections. Analogous versions of pseudorabies are emerging (Oyibo et al. 2014). Transsynaptic labeling approaches based on anterograde viruses remain less well developed. Anterograde labeling methods exist based on the herpes simplex virus but are highly toxic for the infected neurons (Hoover and Strick 1999; Lo and Anderson 2011).

Another strategy for studying specific cells involved in memory processing is to target cells that undergo immediate early gene (IEG) activation at specific phases of a behavioral protocol. Memory researchers often use IEG expression as a neuronal marker of engagement in memory formation, such as via spiking or synaptic plasticity, depending on the particular IEG (Guzowski and Worley 2001; Czajkowski et al. 2014). There are several different types of transgenic mice that permit fluorescence tagging of specific cells according to their patterns of Fos or Arc gene activation (Reijmers et al. 2007; Garner et al. 2012; Liu et al. 2012; Guenthner et al. 2013; Ramirez et al. 2013; Czajkowski et al. 2014; Redondo et al. 2014). Beyond readout of cell activation, IEG-based tagging has chiefly been used in combination with pharmacogenetic or optogenetic means of selectively reactivating or silencing tagged neurons to probe their causal roles in memory processing (Garner et al. 2012; Liu et al. 2012; Ramirez et al. 2013; Cowansage et al. 2014; Redondo et al. 2014; Yiu et al. 2014).

Similar strategies involving IEG-based tagging appear promising for $\mathrm{Ca}^{2+}$-imaging studies. For instance, one might selectively image $\mathrm{Ca}^{2+}$ activity in neurons that underwent IEG activation at an earlier timepoint in a behavioral protocol, to probe how the activity of neurons involved in memory encoding (based on IEG expression) relates to their spiking dynamics at memory recall. More broadly, joint monitoring of IEG expression and $\mathrm{Ca}^{2+}$ imaging might allow comparisons of how information is represented across different sets of neurons, such as those in which Fos, Arc, or other IEGs are activated on different days in a long-term experiment. This type of study might help adjudicate recent hypotheses proposing that the activation of certain IEGs may prime neurons for upcoming bouts of memory storage-before the remembered events have even occurred (Han et al. 2007; Rogerson et al. 2014). Such issues might be fruitfully studied through the use of genetic constructs that express a pair of differently colored fluorescence indicators, one reporting the level of IEG activation and the other signaling $\mathrm{Ca}^{2+}$ activity (Kawashima et al. 2013).

\section{OPTICAL INSTRUMENTATION FOR IN VIVO $\mathrm{Ca}^{2+}$ IMAGING IN AWAKE BEHAVING ANIMALS}

$\mathrm{Ca}^{2+}$-imaging studies in behaving rodents generally use one of two main types of optical instrumentation. In some studies, the animal is head-fixed and behaves in place under the objective lens of a conventional upright two-photon fluorescence microscope (Dombeck et al. 2007; Nimmerjahn et al. 2009). In other studies, the animal carries a miniature fluorescence microscope on its head, thereby allowing $\mathrm{Ca}^{2+}$ imaging studies of neuronal activity during unconstrained animal behavior (Helmchen et al. 2001; Flusberg et al. 2008). Both approaches allow long-term imaging over weeks and have enabled $\mathrm{Ca}^{2+}$-imaging studies of the neurobiology of memory (Komiyama et al. 2010; Harvey et al. 2012; Huber et al. 2012; Ziv et al. 2013; Peters et al. 2014). For a comparison of the optical issues arising in the two imaging formats and discussion of the image analysis algorithms used to extract individual cells' time-varying $\mathrm{Ca}^{2+}$ signals from the fluorescence videos, we refer readers to a recent review of these engineering matters (Hamel et al. 2015). Here we focus on considerations important to the design of scientific studies. 
P. Jercog et al.

A key consideration is whether limiting an animal's range of behavior via head fixation will be a benefit or a drawback. To address many scientific questions, it is crucial to gather data from a large set of stereotyped trials, and the behavioral constraints imposed by head fixation can facilitate both the controlled delivery of sensory stimuli (Verhagen et al. 2007; Carey et al. 2009; Andermann et al. 2011; Blauvelt et al. 2013; Patterson et al. 2013; Miller et al. 2014) and behavioral stereotypy in an animal's responses (Huber et al. 2012; Masamizu et al. 2014; Peters et al. 2014). Together, these capabilities have allowed $\mathrm{Ca}^{2+}$-imaging studies in headfixed animals trained to perform perceptual discrimination (Andermann et al. 2010; Komiyama et al. 2010; O'Connor et al. 2010) and motor execution tasks (Huber et al. 2012; Masamizu et al. 2014; Peters et al. 2014). A recent $\mathrm{Ca}^{2+}$ imaging study even examined a version of associative fear conditioning adapted for headrestrained animals (Lovett-Barron et al. 2014).

In addition to its compatibility with conventional two-photon microscopy, the headrestrained imaging format is also well suited for use with custom-designed fluorescence microscopy setups that provide novel imaging capabilities (Horton et al. 2013; Heys et al. 2014; Lecoq et al. 2014; Low et al. 2014; Quirin et al. 2014; Stirman et al. 2014; Bouchard et al. 2015) or combine two-photon $\mathrm{Ca}^{2+}$ imaging and two-photon optogenetic capabilities in behaving mammals (Packer et al. 2012; Prakash et al. 2012; Rickgauer et al. 2014; Packer et al. 2015). As new optical brain-imaging modalities emerge, the steadily increasing number of behavioral assays for head-fixed rodents will provide valuable test beds for validating novel optical approaches and then capitalizing on the resulting opportunities for biological experimentation.

Head-fixation can also be combined with approaches in which an animal navigates a virtual reality while walking or running in place (e.g., on a spherical treadmill) (Fig. 2) (Holscher et al. 2005; Harvey et al. 2009; Dombeck et al. 2010; Keller et al. 2012; Ravassard et al. 2013; Sofroniew et al. 2014; Aghajan et al. 2015). Virtual reality methods permit sensory manipulations that would be difficult or impossible to achieve in a freely behaving animal (Keller et al. 2012). To date, most virtual reality systems for rodents have involved projection of a visual scene around the head-fixed animal, such as by using a toroidal screen (Fig. 2A,B) (Holscher et al. 2005; Harvey et al. 2009; Dombeck et al. 2010), or arrays of two or more flat video monitors (Fig. 2C) (Keller et al. 2012). However, virtual reality methods that provide tactile feedback are now also emerging (Sofroniew et al. 2014).

A noteworthy caveat is that in an animal exploring a virtual environment, neural dynamics may deviate from their normal forms during unrestrained animal behavior (Ravassard et al. 2013), perhaps because of altered vestibular, self-motion, or visual or tactile sensory inputs. The extent of these effects remains unclear, especially for long-term experiments in which neural plastic effects might accrue over time, and the degree to which different forms of virtual reality impact neural coding remains under active investigation (Ravassard et al. 2013; Aronov and Tank 2014; Aghajan et al. 2015). As computer graphics and reality simulation methods advance, neuroscientists will gain increasingly sophisticated capabilities for performing sensory manipulations during large-scale $\mathrm{Ca}^{2+}$ imaging. Notably, virtual reality methods have been used to study spatial memory in humans in subjects undergoing functional magnetic resonance brain imaging (Pine et al. 2002) or intracranial electrical recordings (Suthana et al. 2012). This commonality might enable parallel studies in which animal and human subjects perform similar tasks, but during different forms of brain imaging suitable for each species.

Complementary to $\mathrm{Ca}^{2+}$-imaging techniques that require head fixation of an alert animal, miniature head-mounted fluorescence microscopes that have flexible cables (optical fibers or floppy electrical lines) allow $\mathrm{Ca}^{2+}$-imaging studies in freely behaving mammals (Helmchen et al. 2001; Flusberg et al. 2008; Sawinski et al. 2009; Ghosh et al. 2011; Ziv et al. 2013; Berdyyeva et al. 2014; Betley et al. 2015; Jennings et al. 2015). The ability to study unrestrained forms of animal behavior is an impor- 
A

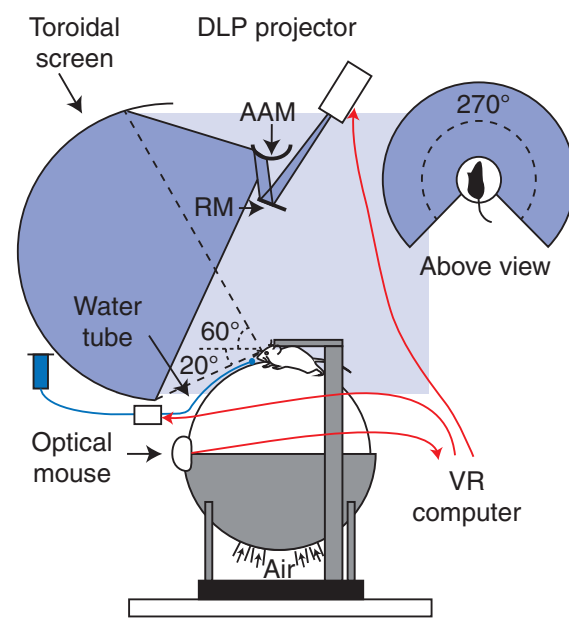

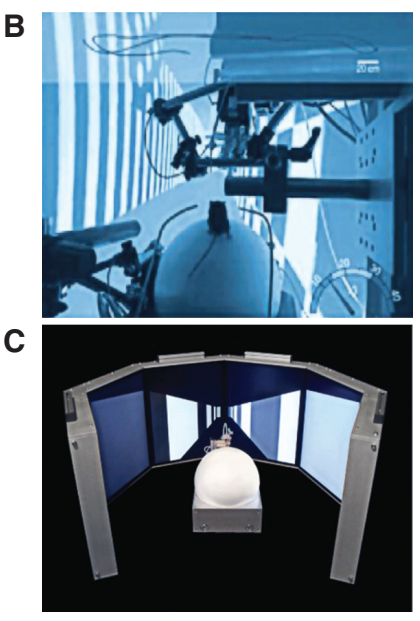

Figure 2. Apparatus for projecting a virtual reality environment. (A) Schematic of a virtual reality apparatus. An image of a virtual space is projected by a digital light-processing (DLP) projector, deflects off a reflecting mirror (RM), and is magnified by a curved, angular amplification mirror (AAM) onto a toroidal screen. A head-fixed rodent is at liberty to walk or run in place on an air-suspended spherical treadmill. An optical computer mouse monitors the treadmill's rotations in both angular dimensions (modified from Harvey et al. 2009; see also Figures 1 and 2 in Holscher et al. 2005). (B,C) Examples of commercially available apparatus, using a toroidal screen, $B$, and a set of six computer screens, $C$, that create virtual environments in which head-fixed rodents can navigate. (Images obtained from and used with permission of PhenoSys GmbH.)

tant capacity, because many animal behaviors are incompatible with or poorly suited to study under conditions of head restraint. Examples include the social behaviors such as fighting, mating, care giving, and other forms of interaction; behaviors probing fear, stress, or anxiety in which head restraint may cause confounding behavioral or physiological effects; and many motor and vestibular-dependent behaviors that involve self-motion cues. All of these behaviors can have learning and memory components. Miniaturized microscopes are also compatible with most of the behavioral assays that are already widely deployed and validated across neuroscience research institutions and in the pharmaceutical industry.

At present, the most widely used miniature fluorescence microscope in the neuroscience research field is a two-gram integrated microscope for $\mathrm{Ca}^{2+}$ imaging in freely behaving mice (Fig. 3A-C) (Ghosh et al. 2011; Ziv et al. 2013). This device is optically integrated in the sense that each two-gram unit contains all required optical components, including a light-emitting diode
(LED) that provides illumination, miniature lenses, a tiny fluorescence filter cube, and a cell phone camera chip that captures the fluorescence images (Fig. 3A,B). Fine electrical wires carry power and control signals to the microscope and convey digital images from the camera chip to an external data-acquisition box. The integrated microscope is commercially available and generally compatible with the spatial mazes, operant chambers, and fear-conditioning boxes commonly used for behavioral studies in mice. With multiple integrated microscopes, one can perform fluorescence $\mathrm{Ca}^{2+}$ imaging in several freely behaving mice in parallel.

When used in conjunction with microendoscope probes (350-1000 $\mu \mathrm{m}$ diameters) that can be permanently implanted deep in brain tissue (Jung and Schnitzer 2003; Jung et al. 2004; Levene et al. 2004; Barretto et al. 2011), the integrated microscope allows brain imaging in a wide variety of different brain areas. These include neocortex, hippocampus, striatum, amygdala, hypothalamus, nucleus accumbens, substantia nigra, and cerebellar cortex 
P. Jercog et al.

A

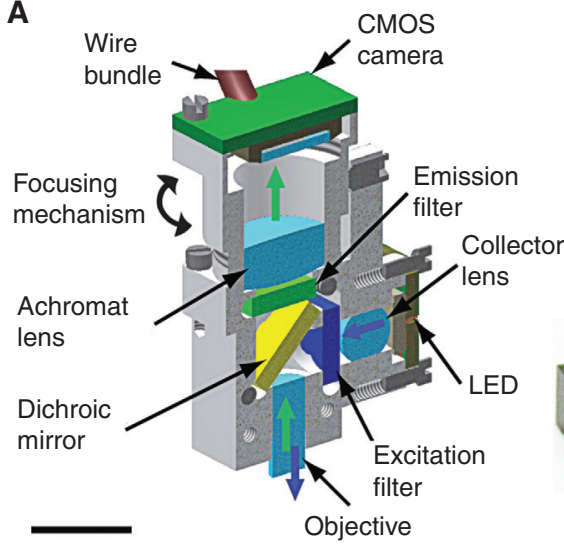

B

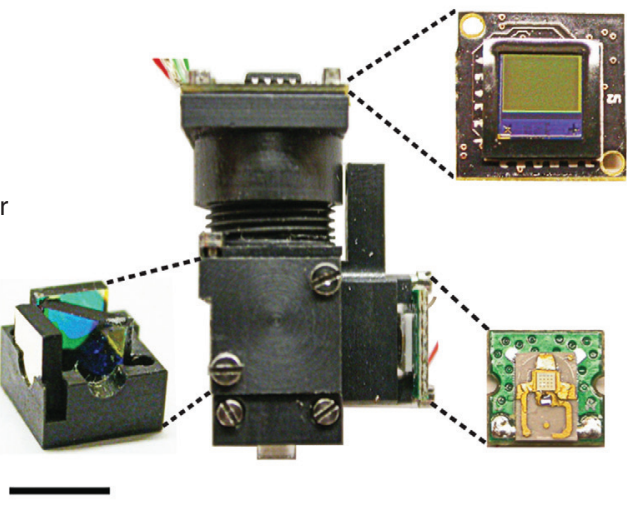

\section{C}

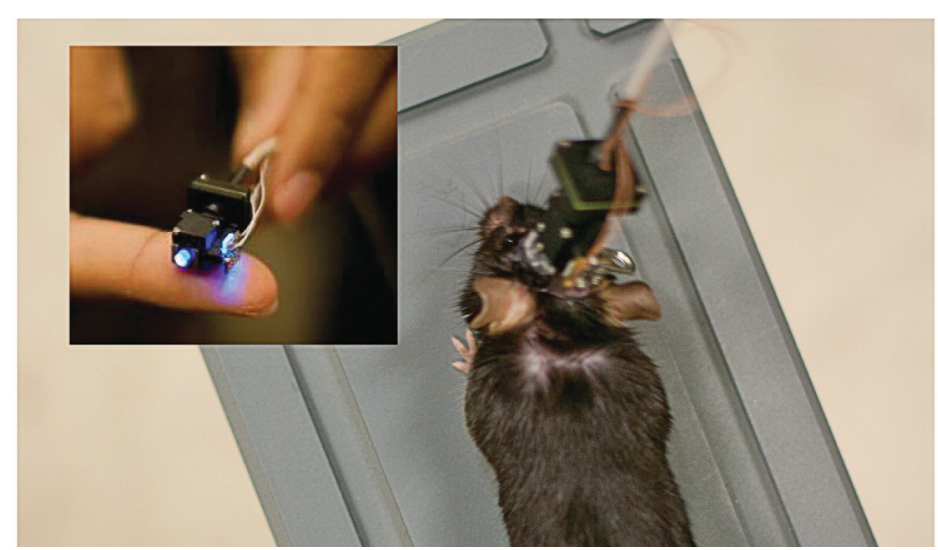

Figure 3. The miniature integrated fluorescence microscope for $\mathrm{Ca}^{2+}$ imaging in freely behaving mice. $(A)$ Computer-assisted design of an integrated fluorescence microscope, showing the optical and mechanical components in cross section. (B) Photograph of an assembled microscope. Insets show the printed circuit boards holding the cell phone camera chip (upper right), the blue light-emitting diode (lower right), and the fluorescence filter cube (lower left). (C) Integrated microscope mounted on a freely behaving mouse. (Inset) An integrated microscope on the tip of a finger. Scale bars, $5 \mathrm{~mm}(A$ and $B)$ and apply also to the insets. Panels $A$ and $B$ are from Ghosh et al. (2011). (Images in panel $C$ are courtesy of Inscopix.)

(Ghosh et al. 2011; Ziv et al. 2013; Grewe et al. 2014; Lefort et al. 2014; Parker et al. 2014; Betley et al. 2015; Hamel et al. 2015; Jennings et al. 2015). To monitor the $\mathrm{Ca}^{2+}$ dynamics of large sets of individual cells in these brain areas across multiple weeks, researchers can repeatedly image the same field of view simply by reattaching the integrated microscope to a permanently affixed cranial base plate at the start of each imaging session (Ziv et al. 2013). Electroencephalography or electromyography recordings can also be performed simultaneously with $\mathrm{Ca}^{2+}$ imaging, such as for monitoring brain or loco- motor states (Berdyyeva et al. 2014). A single field of view $\left(\sim 0.5-0.6 \mathrm{~mm}^{2}\right)$ from the integrated microscope can routinely reveal many hundreds of neurons over the course of an extended $\mathrm{Ca}^{2+}$-imaging study (Ziv et al. 2013), and sometimes $>1000$ cells (Fig. 4) (Alivisatos et al. 2013).

We expect that the optical methods for $\mathrm{Ca}^{2+}$ imaging in head-restrained and freely behaving animals will both continue to advance in their capabilities. Likely improvements include optical access to greater numbers of cells per animal, fast volumetric imaging, multicolored $\mathrm{Ca}^{2+}$ 
A

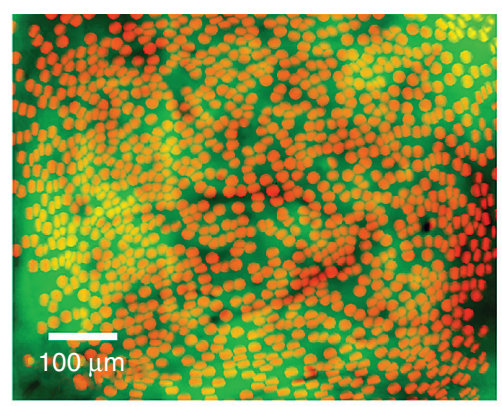

B

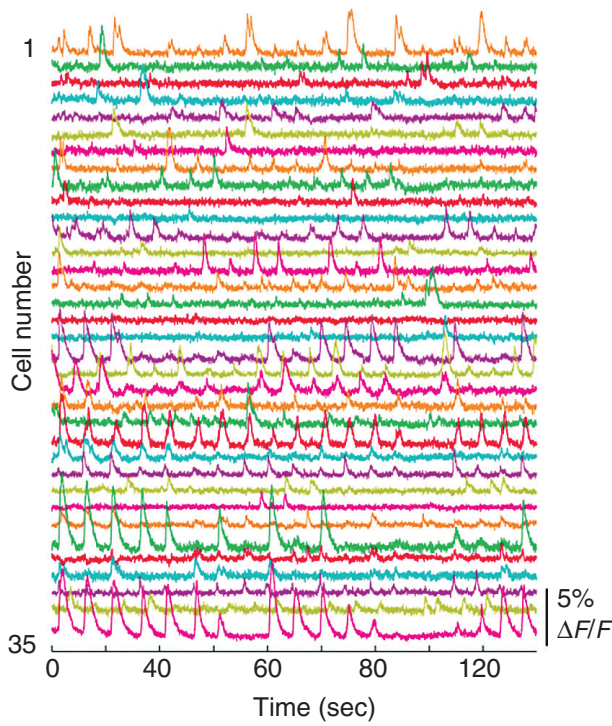

Figure 4. $\mathrm{A} \mathrm{Ca}^{2+}$-imaging dataset from a single freely behaving mouse can contain $\sim 1000$ neurons. $(A)$ 1202 GCaMP-expressing CA1 hippocampal pyramidal neurons (red somata), identified in $\mathrm{Ca}^{2+}$-imaging data taken in a freely moving mouse using the integrated microscope, shown atop a mean fluorescence image (green) of CA1. Vessels appear as dark shadows (from Alivisatos et al. 2013). (B) 35 example traces of $\mathrm{Ca}^{2+}$ activity from CA1 hippocampal pyramidal neurons expressing GCaMP3 under the control of the Camk2a promoter (modified from supplementary Fig. 1b in Ziv et al. 2013).

imaging for monitoring two targeted subpopulations of cells simultaneously, imaging in multiple brain areas concurrently, and superior capabilities for simultaneous $\mathrm{Ca}^{2+}$ imaging and optogenetic manipulation. These capacities will further expand the pregnant set of possibilities for optical studies of memory in behaving animals.

\section{ADVANTAGES OF $\mathrm{Ca}^{2+}$ IMAGING FOR ANALYSES OF LONG-TERM MEMORY}

Beyond its capacities for recording from many individual cells and targeting cells of specific types, both of which are generically useful for systems neuroscience, $\mathrm{Ca}^{2+}$ imaging offers additional capabilities that are especially valuable for studies of long-term memory. The latter include the abilities to track individual neurons over many weeks, isolate the signals of neurons with very low activity rates, and visualize the anatomical organization of information processing at cellular resolution. These three facilities have specific import for the learning and memory field.

Long-term memories can persist from timescales of hours to years. To understand how neural ensembles maintain stored information, it is important to have recording techniques that can monitor individual cells' dynamics over time spans commensurate with the memory durations of interest. Hence, chronic animal preparations for time-lapse in vivo imaging offer key benefits for studies of long-term memory. Time-lapse fluorescence imaging in live adult mice has provided a potent means for repeatedly inspecting the same neurons and even the same dendritic spines, over periods ranging from weeks to over a year (Grutzendler et al. 2002; Trachtenberg et al. 2002; Zuo et al. 2005; Chen et al. 2008, 2012a; Holtmaat et al. 2009; Yang et al. 2009, 2014b; Cruz-Martin et al. 2010; Fu et al. 2012; Lai et al. 2012; Mostany et al. 2013; Attardo et al. 2015). When this capability is combined with $\mathrm{Ca}^{2+}$ imaging, one can track individual neurons' coding properties over weeks with an ease and efficiency that has been lacking from electrophysiological techniques (Huber et al. 2012; Ziv et al. 2013; Peters et al. 2014).

Traditional electrophysiological recording methods have allowed researchers to track the spiking dynamics of modest numbers of individual cells over days to weeks (Thompson and Best 1990). A majority of such long-term electrophysiological studies has focused on the rodent hippocampus, a crucial brain area for the formation of spatial and episodic memories 
P. Jercog et al.

(Eichenbaum 2000; Buzsaki and Moser 2013). Early reports (Muller et al. 1987; Thompson and Best 1990) of long-term electrical recordings in the hippocampus described longer recording durations than those typical of more recent studies (Lever et al. 2002; Kentros et al. 2004; Muzzio et al. 2009; Mankin et al. 2012; McKenzie et al. 2014). For instance, in rats that repeatedly explored a familiar spatial environment, Thompson and Best (1990) reported that 10 hippocampal neurons maintained stable place fields for 6-153 days. By comparison, recent studies of hippocampal coding have generally tracked greater numbers of cells over briefer durations. For instance, Mankin et al. (2012) reported that they maintained electrical recordings from 30 neurons in three rats over 3 days. Muzzio et al. (2009) followed 65 neurons in 14 mice for 4 days. McKenzie et al. (2014) tracked 38 neurons in four rats over 2 days.

This trend toward more cells and shorter recording durations is probably a reflection of increasingly sophisticated analyses of neural coding and the resulting need for datasets with greater numbers of cells, rising appreciation for the importance of repeatability within individual studies and reproducibility by other labs, and progressive improvements in the statistical rigor of the spike sorting procedures used to identify and track individual cells' spike waveforms. Crucially, studies based on chronic electrical recordings should include statistical tests confirming that the variations between individual cells' spike waveforms across consecutive recording days are smaller than the variations between the waveforms of neighboring cells recorded on the same day. Without this, the argument that electrical recordings suffer minimal drift over time is compromised. Overall, the technical challenges inherent to maintaining stable electrical recordings in behaving animals have limited the recording durations and numbers of neurons used for analyses of memory codes. This in turn has constrained the complexity of the questions about longterm memory that researchers have been able to address empirically. Hence, a major advantage of $\mathrm{Ca}^{2+}$ imaging is the ability to follow hundreds of individual neurons in a single an- imal over weeks (Ziv et al. 2013; Peters et al. 2014) yielding datasets that electrical recordings cannot match in statistical power for analyses of neural coding.

In addition to increasing the number of cells whose activity can be tracked in vivo, $\mathrm{Ca}^{2+} \mathrm{im}$ aging allows researchers to reliably track neurons with very low rates of activity. The ability to monitor such cells is important, because even neurons with very low activity rates can make substantial contributions to information coding if their spikes convey reliable signals. With extracellular electrical recording methods, a certain minimum number of spikes is required to isolate and extract the action potentials from an individual cell by spike sorting, because of the statistical variability of action potential waveforms. This makes it nearly impossible for researchers to track a neuron across 1 or more days of electrical recording in which the neuron fired no spikes. By comparison, in long-term $\mathrm{Ca}^{2+}$. imaging studies one tracks individual cells across days by image registration (i.e., by aligning the fluorescence images across imaging sessions). Such image alignment can often be done to $<1 \mu \mathrm{m}$ scale accuracy and does not depend critically on cells' activity rates (Ziv et al. 2013). Hence, with $\mathrm{Ca}^{2+}$ imaging one can track a neuron's dynamics even across long recording epochs in which it is silent. An electrophysiologist experienced with extracellular recordings might argue that this advantage of $\mathrm{Ca}^{2+}$ imaging is mainly a theoretical one, because in practical experience neurons are rarely perfectly silent for extended durations. It is important to remember that any such appeal to experience is based on the specific subset of neurons that can be followed electrically and neglects the cells that are too silent for spike sorting.

Indeed, neuroscientists are increasingly realizing that extracellular electrical recordings may often provide a sampling of cells that is biased toward active cells (Lutcke et al. 2013). Studies using intracellular whole-cell patch electrical recordings in both head fixed (Margrie et al. 2002) and freely behaving (Lee et al. 2006) animals support this observation. To achieve whole cell patch electrode recordings the physiologist identifies a neuron from its 
membrane impedance, not its spiking activity (Margrie et al. 2002). Hence, like $\mathrm{Ca}^{2+}$ imaging, these recordings can sample very quiet cells, and the mean neuronal activity rates obtained with the two techniques are broadly consistent. For example, whole cell recording and $\mathrm{Ca}^{2+}$-imaging studies of the rodent motor cortex reported spiking and $\mathrm{Ca}^{2+}$ transient rates of $\sim 0.01-$ $1.8 \mathrm{~Hz}$ (Lee et al. 2006) and $\sim 0.001-0.15 \mathrm{~Hz}$ (Komiyama et al. 2010; Huber et al. 2012), respectively, one or more orders of magnitude lower than those observed by extracellular recording $(\sim 1-2 \mathrm{~Hz})$ (Laubach et al. 2000). In one $\mathrm{Ca}^{2+}$-imaging study of motor learning the rates of motor cortical neuron activation were as low as $\sim 3.6-0.7$ spikes per hour (Huber et al. 2012). Neurons with activity rates this low would be highly challenging to isolate by extracellular electrical recording methods. The degree to which the different methods will yield activity rates out of accord with one another will clearly vary by brain area, cell type, and behavioral state. Regardless of the exact extent of such differences, the ability to follow quiet neurons is especially important for studies of long-term memory, because different subsets of cells may be active on different days (Ziv et al. 2013; Peters et al. 2014).

Recent time-lapse imaging studies of neural ensembles in hippocampus and motor cortex well illustrate $\mathrm{Ca}^{2+}$ imaging's methodological advantages. To study the long-term dynamics of CA1 ensemble place codes, Ziv et al. (2013) performed $\mathrm{Ca}^{2+}$ imaging in mice exploring a familiar environment and tracked 515-1040 individual CA1 hippocampal pyramidal cells across 45 days in each of four mice (Fig. 5). It was important to verify that when monitored by $\mathrm{Ca}^{2+}$ imaging, CA1 neurons displayed coding attributes normally expected of place cells. As anticipated, many neurons exhibited $\mathrm{Ca}^{2+}$ activity when the mouse explored a specific portion of its arena. Many of the optically determined place fields remapped when the mouse was transferred to a different arena placed at the same location in the laboratory room, as reported previously (Leutgeb et al. 2005). When the mouse explored a linear track, the set of place fields fully covered the track, and many neurons had statistically significant place fields when the mouse was heading in only one of the two possible running directions, matching past observations (McHugh et al. 1996). About 20\% of the cells seen in individual imaging sessions had significant place fields for one or both running directions, and the sizes of the place fields determined by $\mathrm{Ca}^{2+}$ imaging were consistent with prior reports (Dombeck et al. 2010; McHugh et al. 1996; Rotenberg et al. 1996; Nakazawa et al. 2003). These observations lent confidence that the pyramidal cells' $\mathrm{Ca}^{2+}$ activation patterns accurately conveyed their place coding properties. By tracking these coding properties as the mice explored the linear track during sessions spaced at 5-day intervals, Ziv et al. (2013) attained some unexpected findings regarding the long-term dynamics of the CA1 representation of a familiar environment.

Notably, there was substantial turnover from session to session in the set of neurons that displayed $\mathrm{Ca}^{2+}$ activity (Fig. 5A,B). Only $31 \pm 1 \%$ (mean \pm s.D.) of all neurons seen across the entire experiment were active in any one session, and this percentage was constant over the entire study (Fig. 5B, inset). Across sessions, individual cells came in and out of this active subset in an apparently random manner (Fig. 5A,B), and the overlap in the active subsets from different days declined moderately from $\sim 60 \%$ for sessions 5 days apart to $\sim 40 \%$ for 30 days apart (Fig. 5C). Among the cells that had statistically significant place fields in one or more sessions, the overlap in these coding subsets from different days was $\sim 25 \%$ for sessions 5 days apart and $\sim 15 \%$ for sessions 30 days apart (Fig. 5C). Thus, even in a familiar environment there is substantial dynamism in the CA1 ensemble representation of space. Strikingly, the odds of a cell's recurrence in either the active or coding ensembles were uncorrelated with the rate and amplitude of its $\mathrm{Ca}^{2+}$ activity and with the stability of its place field within individual sessions. However, when individual cells did show place fields in more than one session, the place fields' locations on the linear track were nearly always unchanged (Fig. 5D). Thus, individual cells' place fields were spatially invariant but temporally stochastic in their day-to-day appearances. 
P. Jercog et al.

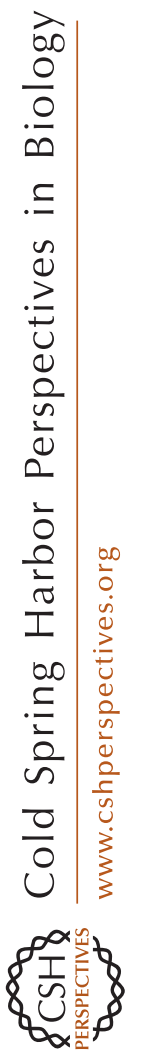

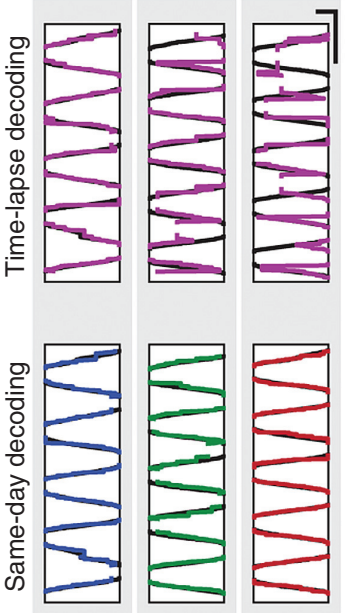

$\boldsymbol{\omega}$ ot Keo oz Keo se אeо

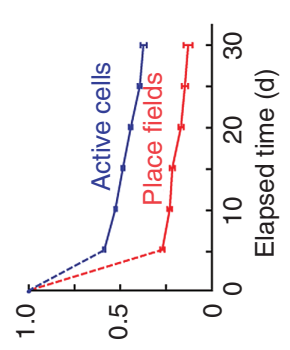

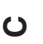

K!!!!qeqoıd әэиәлипэәу

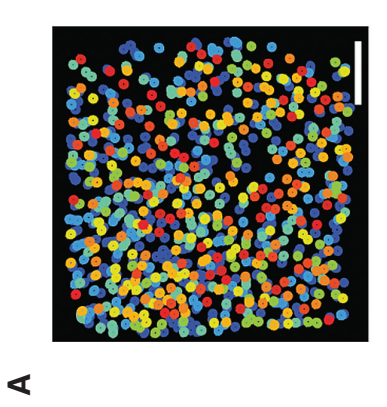

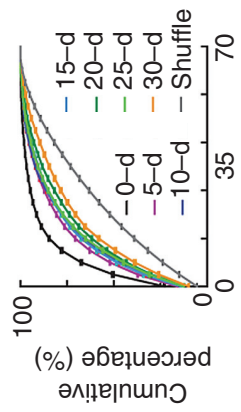

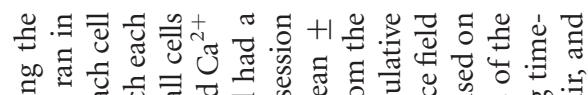

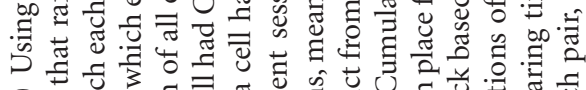

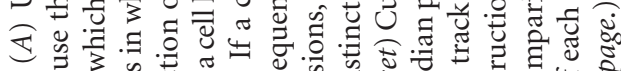

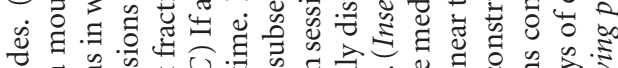
ठठ 0 है

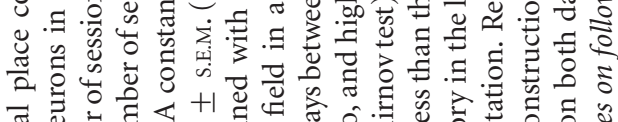

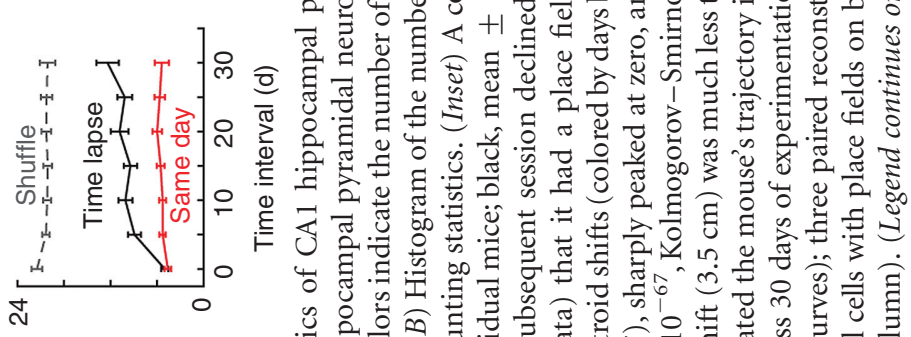

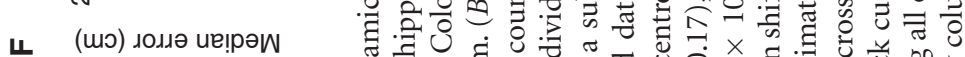

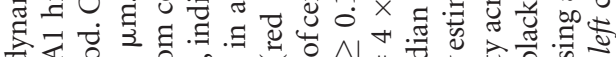

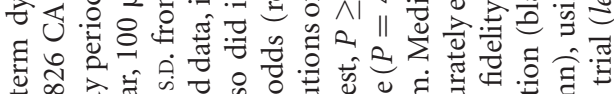

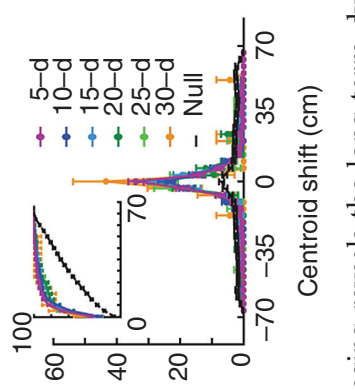

(\%) sp|ə!! әэе|d
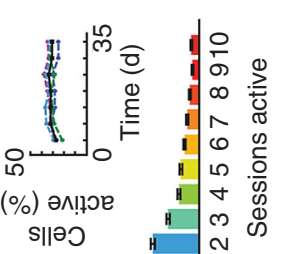

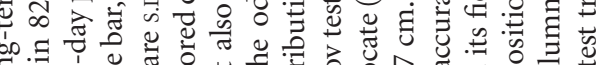

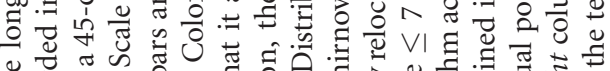

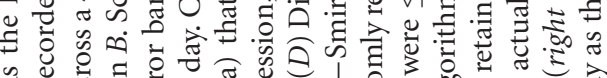

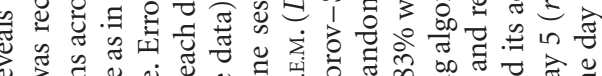

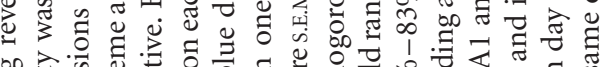

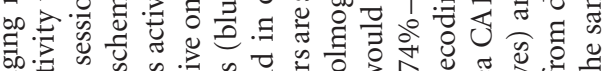

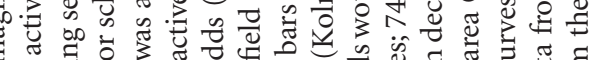
+ 000 \%

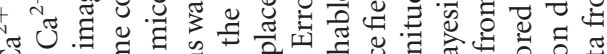

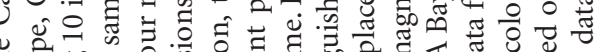

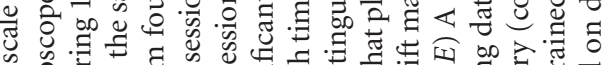

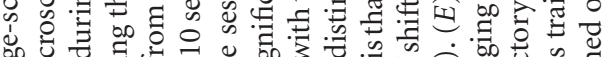

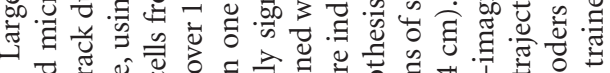

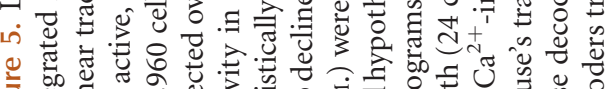

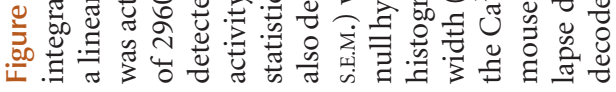

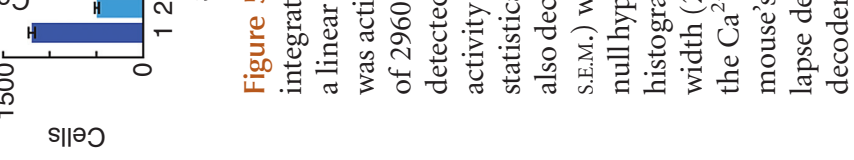


Is $\sim 15 \%-25 \%$ overlap in the set of cells with significant place fields sufficient to maintain a stable representation of space over weeks? To address this question, Ziv et al. (2013) used computational decoding methods to analyze the spatial information content of the ensemble activity patterns. With datasets containing 515-1040 cells per mouse, it was possible to reconstruct each animal's locomotor trajectory using the representations of space encoded within the ensemble neural dynamics. Despite individual cells' fluctuating contributions to place coding across different imaging sessions, the ensemble representations of space maintained their coding fidelity for at least a month (Fig. 5D-G) (Ziv et al. 2013). In essence, this fidelity at the ensemble level arose from the spatial invariance of the individual cells' place fields when they recurred.

Overall, the results of Ziv et al. (2013) suggest quite a different picture of hippocampal spatial coding than had emerged from electrophysiological studies. Certainly, the $\mathrm{Ca}^{2+}$ imaging and electrophysiological data are mutually consistent, in that both reveal individual CA1 neurons that stably express place fields over the long term. However, through its capabilities for tracking neurons across sessions in which the neurons are silent, $\mathrm{Ca}^{2+}$ imaging reveals that such long-term stability is not the norm. For each location in a familiar environment, it seems there are more than enough cells with corresponding place fields to encode the mouse's position; only a portion of these cells are active in any one session, but this portion is sufficient for stable spatial coding. What is the functional role of the $\sim 75 \%-85 \%$ of coding cells that do not overlap between any two sessions?

One possibility is that this $\sim 75 \%-85 \%$ of cells endows each episode with a unique neural signature, potentially allowing the hippocampus to retain distinct memories of the different episodes while preserving information about the shared environment in the other $\sim 15 \%-25 \%$. Although speculative, this proposition about episodic memory storage should be experimentally testable, by using long-term $\mathrm{Ca}^{2+}$ imaging, decoding analyses, and well-controlled behavioral assays to dissect different cells' contributions to memories' spatial and episodic components. By combining $\mathrm{Ca}^{2+}$ imaging with molecular manipulations, or with other optical approaches such as fluorescence tagging (Reijmers et al. 2007; Liu et al. 2012; Guenthner et al. 2013; Kawashima et al. 2013; Ramirez et al. 2013; Redondo et al. 2014) and long-term imaging of CA1 dendritic spines (Attardo et al. 2015), it should also be possible to study the mechanisms underlying the spatial stability of the place fields and the temporal variability of their expression.

Another illustration of the substantial statistical analyses that are feasible using large-scale $\mathrm{Ca}^{2+}$-imaging data comes from a study of the mouse motor cortex that tracked $\sim 200$ neurons in each of 10 mice as the animals learned a leverpress task over 14 days (Fig. 6A-G) (Peters et al. 2014). The data revealed substantial reorganization and refinement of the ensemble neural dynamics over the course of motor learning. During the first 3 days, the number of neurons with movement-related activity patterns approximately doubled, from $\sim 10 \%$ to $\sim 20 \%$; across subsequent days, the number of such cells gradually returned to near its initial value (Fig. 6A). Throughout training, the timing of neural responses relative to movement onset gradually became less variable (Fig. 6B) and more correlated across movement trials (Fig. 6C-E).

Moreover, as the mice became expert and learned a stereotyped movement, the neural en-

Figure 5. (Continued) Each pair used an equal number of cells, optimally chosen at left to minimize errors. Scale bars, $2 \mathrm{sec}$ (horizontal) and $10 \mathrm{~cm}$ (vertical). (F) Median errors in estimating the mouse's position were $\sim 7-$ $13 \mathrm{~cm}$, even for decoders trained on data from 30 days prior (black, mean \pm S.E.M.). (Red) Decoders trained on data from the same day as test data, using equal numbers of cells as black points and optimally chosen to minimize errors. (Gray) Errors using shuffled traces of $\mathrm{Ca}^{2+}$ activity from the same day as training data (averaged over 10,000 shuffles). ( $G$ ) Cumulative distributions of decoding error magnitudes (mean \pm s.E.M.) for test and training data separated by the indicated times or (gray) for decoders tested on shuffled data (all panels are from Ziv et al. 2013). 
P. Jercog et al.
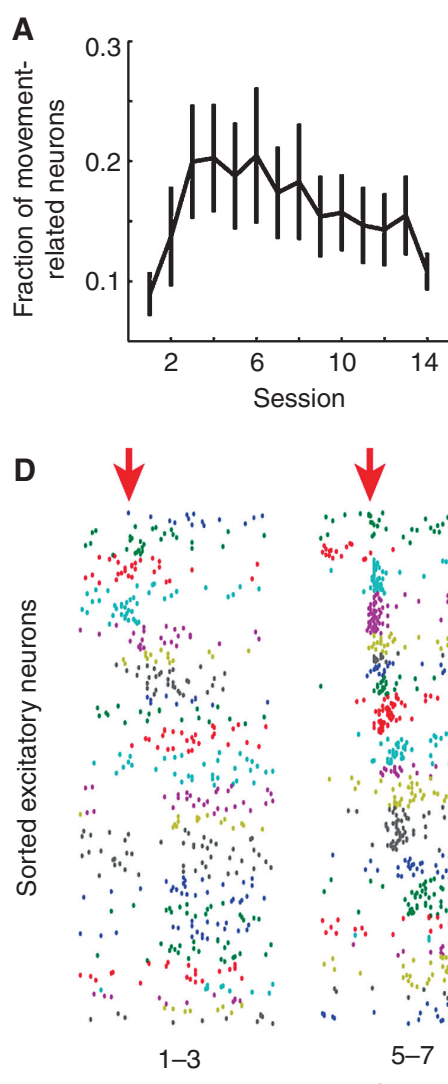

$\mathbf{F}$

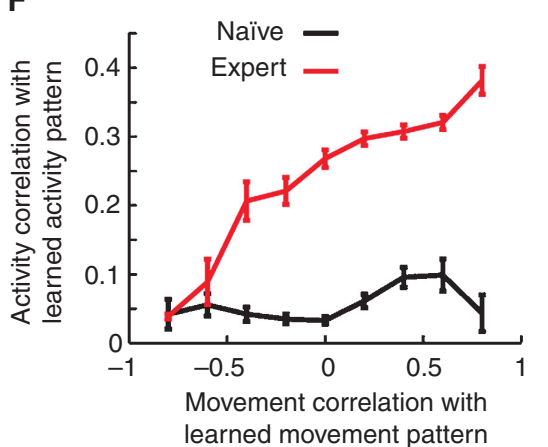

B

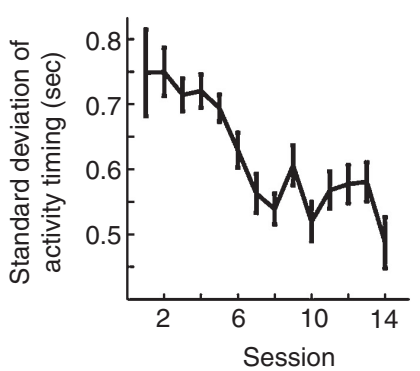

C
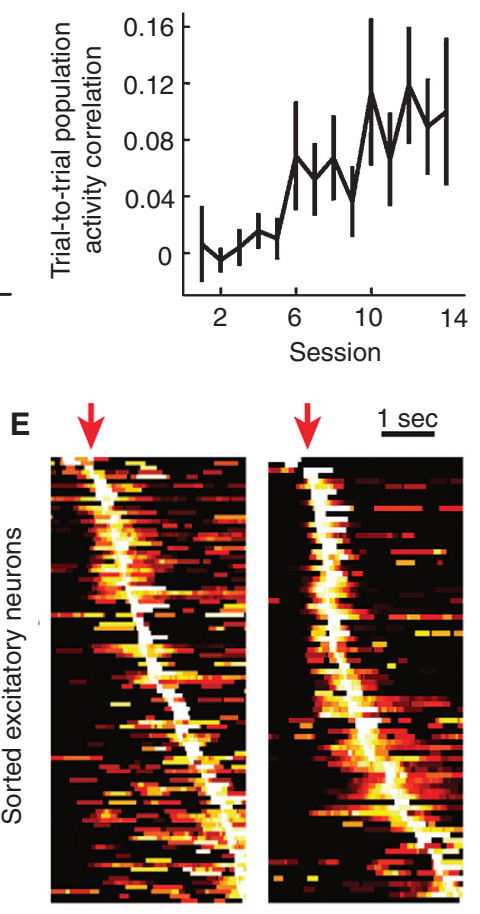

Session 2

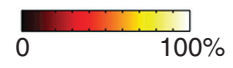

Normalized $\Delta F / F$

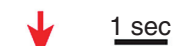

G

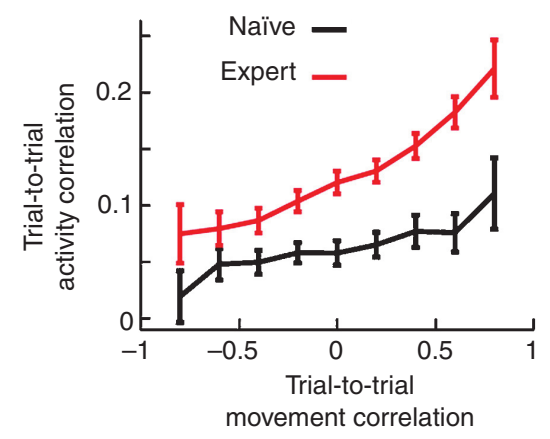

Figure 6. Large-scale $\mathrm{Ca}^{2+}$ imaging reveals the reorganization of ensemble neural dynamics in mouse layer $2 / 3$ motor cortical neurons across a 2-week regimen of daily motor learning. (A) Fraction of excitatory neurons classified as movement related in each of the 14 training sessions, during which mice learned a lever-press task. (B) Standard deviation of the timing of activity onsets for movement-related excitatory neurons for neurons that were active in five or more sessions. The trial-by-trial variability in the onset of single cell activity declined as learning progressed. $(C)$ Ensemble neural activity became more stereotyped as learning advanced, as shown by the increase in the pairwise trial-to-trial correlation of temporal population activity vectors. The temporal population activity vector was a concatenation of the activity traces of all movement-related neurons and thus maintained temporal information within each movement. (D) Neuronal activity increased in temporal structure over the course of motor learning. Raster plots of neuronal $\mathrm{Ca}^{2+}$ activity for movement-related neurons that were active in at least $10 \%$ of trials on the sessions indicated, shown for an example animal. Red arrows indicate movement onset. (Legend continues on following page.) 
sembles gradually acquired stereotyped activity patterns, and the degree to which the ensemble dynamics on individual trials resembled these stereotyped patterns was predictive of the degree to which the animal's movement resembled its expert, stereotyped form (Fig. 6F,G). However, even in mice that were expert at performing stereotyped movements, there remained substantial trial-to-trial variability in neurons' responses (Fig. 6F,G). Like the variability in CA1 place cells' dynamics that left ensemble spatial coding fidelity largely intact, this finding suggests that stable retention of information at the level of neural populations does not require purely stable neuronal firing properties. On the contrary, neural ensembles may be far more robust in their information-processing capabilities than can be inferred from the activity patterns of individual cells.

Notably, though $\mathrm{Ca}^{2+}$ imaging affords access to the topographic organization of memory at a cellular scale, the recent imaging studies of both hippocampus and motor cortex did not find any clear anatomical patterns by which cells with similar coding properties are organized (Dombeck et al. 2010; Ziv et al. 2013; Peters et al. 2014). Instead, the arrangements appeared to be random. Similarly, a recent study of piriform cortex yielded evidence that cells involved in storing learned odor memories are also randomly organized (Choi et al. 2011). By comparison, a recent $\mathrm{Ca}^{2+}$-imaging study of medial entorhinal cortex found a clear micro-organization in the anatomical arrangements of grid cells (Heys et al. 2014). In sensory and motor brain areas there are well-known topographic maps that relate neurons' anatomic locations and coding properties to specific features of the sensory world or the animal's body plan (Albright et al. 2000). Particularly in cognitive but also in motor areas, the manner in which information processing is organized at the cellular scale remains far less explored. Plainly, large-scale in vivo $\mathrm{Ca}^{2+}$ imaging provides a potent new tool to do so, for multiple forms of information processing (Dombeck et al. 2010; Ziv et al. 2013; Heys et al. 2014; Peters et al. 2014).

Overall, $\mathrm{Ca}^{2+}$ imaging permits memory researchers to probe aspects of neural coding that have been inaccessible from electrical recordings. The sheer number of neurons that neuroscientists can now reliably image over weeks enables wholly new analyses of how ensemble codes form, evolve, and are refined over the course of memory encoding, consolidation, maintenance, and recall. As individual neurons enter, exit, or return to the ensemble codes involved in memory processing, neuroscientists can track these cellular transitions, even over extended time periods during which some of the individual cells are silent. By using $\mathrm{Ca}^{2+}$ imaging, memory researchers can also examine how cells' anatomical arrangements relate to their memory processing roles. Each of these new capacities will likely provide important insights regarding the brain's rules and mechanisms for handling memory data.

Figure 6. (Continued) Colors distinguish individual neurons that have been sorted according to their preferred timing. Note that the same color across different sessions does not necessarily mark the same neurons. $(E)$ Maximum-normalized average activity from all movement-related neurons from all animals in session 2 (106 neurons) and session 14 (84 neurons) aligned to movement onset (red arrow). The timing of neuronal activity was more refined in session 14, as evidenced by the narrower peaks and lower levels of background activity, and the timing shifts toward movement onset. $(F)$ In expert but not naïve mice, the extent to which ensemble neural activity in individual trials correlated with the average learned neural activity pattern from expert sessions was predictive of the extent to which the animal's movement pattern correlated with the learned movement pattern. In sessions during which the mice were naïve, when the animals made movements that resembled the learned movement patterns acquired later in training, the underlying neural activity patterns were nevertheless very different from the learned neural activity pattern late in training. $(G)$ Pairwise trial-to-trial correlation of temporal population neural activity vectors (as in $C$ ) plotted as a function of movement correlation on those trials. A stronger relationship between ensemble neural activity and movement emerges during learning. All error bars are S.E.M. (all panels are modified from Peters et al. 2014). 
P. Jercog et al.

\section{PROSPECTS FOR STUDYING THE ORGANIZATION OF MEMORY USING $\mathrm{Ca}^{2+}$ IMAGING}

Memories are often linked to one another, such as through associations and shared attributes, and organized into structures such as categories, sequences, and hierarchies. By providing the means to examine the ensemble neural codes supporting two or more different memories, in vivo $\mathrm{Ca}^{2+}$ imaging offers intriguing prospects for directly visualizing the biological instantiation of memory organization. The large numbers of neurons that can be monitored currently by $\mathrm{Ca}^{2+}$ imaging will likely be crucial for this pursuit, because substantial statistical power will be necessary to determine the extent to which related memories are supported by overlapping neural representations, and whether these representations use local or distributed coding schemes. Moreover, the brain's memory representations are generally dynamic and involve multiple brain regions to varying extents at different stages of memory processing. As a memory becomes more remote in time, the reshaping of its representation across different brain areas is known as systems memory consolidation (Dudai 2004; Frankland and Bontempi 2005). Time-lapse $\mathrm{Ca}^{2+}$-imaging studies may provide a window onto these events at the cellular scale in live animals.

A large body of research in psychology and cognitive neuroscience has focused on the extent to which memory representations are local or distributed, and how such representations encode the relationships between different memories. There is a spectrum of theoretical possibilities (Quian Quiroga and Kreiman 2010). In theories at the "localist" end of the spectrum (Page 2000; Bowers 2009), individual memories reside within individual cells; cell identities provide individual memories their unique codes or signatures and synaptic connections link different memories together. By comparison, in theories involving fully distributed representations, individual cells are generally involved in the encoding of multiple memories (Rumelhart et al. 1986; Masson 1987; Plaut and McClelland 2010); in these theories, it is the distributed patterns of neural activity that provide unique signatures to individual memories, hence, memories can only be deciphered from the population-level activity patterns and not the dynamics of individual neurons. Clearly, there are many intermediate possibilities as well, melding these aspects of representation for different facets of memory and across different brain structures. Notably, the vast majority of such ideas from cognitive science have not yet been tested empirically through biological studies of neural dynamics. In vivo $\mathrm{Ca}^{2+}$-imaging studies might change this situation, by enabling direct observations of the extent to which cell identities or activity patterns provide memories their signatures-at least in ensembles of cells that can be imaged simultaneously.

In addition to the newfound experimental possibilities for examining whether memory representations are local or distributed, $\mathrm{Ca}^{2+}$ imaging also offers new means to examine the manner in which the brain encodes associations, which can link different parts of an individual memory and relate different memories to each other. Consider an example $\mathrm{Ca}^{2+}$-imaging study of second-order associative conditioning. Presently, there are ongoing $\mathrm{Ca}^{2+}$-imaging studies of first-order associative learning in brain structures such as the amygdala and nucleus accumbens (Grewe et al. 2014; Parker et al. 2014), and it is reasonable to envision these experiments could be suitably extended. In second-order conditioning (Gewirtz and Davis 2000; Debiec et al. 2006), an animal first experiences paired presentations of an initially neutral conditioned stimulus $\left(\mathrm{CS}_{1}\right)$ and an unconditioned stimulus (US) that evokes an unconditioned behavioral response. With learning, the animal gains a conditioned response to $\mathrm{CS}_{1}$. A second conditioned stimulus $\left(\mathrm{CS}_{2}\right)$ is then paired with $\mathrm{CS}_{1}$; afterward, a presentation of $\mathrm{CS}_{2}$ evokes the conditioned response despite that $\mathrm{CS}_{2}$ was never directly paired with the US. How is the relationship between the US and $\mathrm{CS}_{2}$ encoded?

One proposal is that the individual representations of $\mathrm{CS}_{1}$ and $\mathrm{CS}_{2}$ involve overlapping populations of neurons (Debiec et al. 2006). However, any such overlap has not been directly 
observed, in part because of the long-standing inability to visualize ensemble neural activity throughout learning and memory formation. By using in vivo $\mathrm{Ca}^{2+}$ imaging in a brain area that has been implicated in forming the associations for a particular form of learning, it may be feasible to directly examine the neural codes involved. Specifically, it should be possible to visualize the extent to which the cellular representations of $\mathrm{CS}_{2}, \mathrm{CS}_{1}$, and the US overlap, as determined from the subsets of neurons activated by each stimulus. Of key interest is the manner in which the representation of the association between $\mathrm{CS}_{2}$ and the US depends on the prior association between $\mathrm{CS}_{1}$ and the US. Will the associative relationships be encoded by overlapping cellular memberships in the representations (Debiec et al. 2006), distinctive signatures in the neural ensemble activity (Buzsaki 2005; Buzsaki and Moser 2013), combinations thereof, or means that are not observable by $\mathrm{Ca}^{2+}$ imaging? More generally, a second-order association is only one type of relationship between memories, and $\mathrm{Ca}^{2+}$ imaging might help elucidate the organization of neural codes and their interrelationships for multiple other forms of learning. For example, categorical memories may arise from more elementary ones, and future $\mathrm{Ca}^{2+}$-imaging studies might allow sophisticated analyses of this process.

A related set of issues concerns the temporal relationships between different memories and the manner in which new information is encoded in relation to prior memories. The biological mechanisms that govern the encoding of temporal relationships are only starting to be uncovered. Notably, neurons expressing virally induced, elevated levels of the cAMP-response element-binding protein (CREB) appear to have increased electrical excitability and may be primed for upcoming bouts of memory storage (Han et al. 2007, 2009; Zhou et al. 2009; Yiu et al. 2014). Further, neurons that have recently encoded a memory, as assessed by CREB phosphorylation, maintain their elevated levels of phosphorylated CREB and presumed heightened excitability for several hours following learning; this persistence of CREB activation may bias the storage of subsequent memories toward the same set of excitable neurons encoding the first memory (Silva et al. 2009). Thus, two learning episodes that are temporally separated, but within the time window of CREB activation, may be encoded in overlapping populations of neurons, thereby forming an association between the two memories in the brain (Rogerson et al. 2014). Similarly, behavioral (Ballarini et al. 2009) and cell biological (Frey and Morris 1997) phenomena in which one set of events impacts the encoding of other temporally separated events indicate that memories are not encoded in isolation, but rather in relation to prior and subsequent events (Moncada and Viola 2007). To investigate issues of this kind, multiple studies to date have examined memory representations via patterns of IEG activation (Guzowski et al. 1999; Frankland and Bontempi 2005; Reijmers et al. 2007; Goshen et al. 2011; Tse et al. 2011; Czajkowski et al. 2014), but $\mathrm{Ca}^{2+}$-imaging datasets might offer richer possibilities for analyses of the spatiotemporal features of ensemble neural coding.

Another important aspect of memory organization that may be ripe for study by $\mathrm{Ca}^{2+}$ imaging is systems memory consolidation ( Dudai 2004; Frankland and Bontempi 2005). Substantial literature suggests that as a stored memory becomes more remote, neocortical memory systems may gradually extract and reorganize memory information from an initially acting memory system such as hippocampus (McClelland et al. 1995), eventually obviating the necessity of hippocampus for memory recall (Scoville and Milner 1957; Kim and Fanselow 1992; Squire and Alvarez 1995; Wiltgen et al. 2004; Bontempi and Durkin 2007; Tse et al. 2007, 2011). These rearrangements of memories across brain areas might allow the neocortex to organize information in a more abstract form (Fuster 2009), such as by using schemas that establish higher-order associations and categories of information or knowledge (Piaget et al. 1929; Bartlett 1932; van Kesteren et al. 2012; McKenzie et al. 2013; Preston and Eichenbaum 2013).

However, because of the extended time course of systems consolidation, from weeks in rodents (Kim and Fanselow 1992) to years in 
P. Jercog et al.

humans (Scoville and Milner 1957; Squire and Alvarez 1995), the relevant interactions between neural ensembles in hippocampus and neocortex remain unknown. By using timelapse $\mathrm{Ca}^{2+}$-imaging ability to track neuronal ensembles over extended durations, researchers might conceivably be able to watch how large sets of individual neurons in different brain regions exchange information. Optical methods for imaging multiple brain areas concurrently (Lecoq et al. 2014), including hippocampus and neocortex, may be especially useful.

Recent studies in rodents have also challenged the long-held notions that the engagement of neocortex in systems consolidation is always slow (Tse et al. 2007; Tse et al. 2011), and that the necessity of hippocampus for memory recall always diminishes over the course of long-term memory storage (Wiltgen et al. 2010; Goshen et al. 2011). By using IEG expression as a readout of cellular involvement in memory formation, studies in rats have shown that once a schema is established, the neocortex can be directly activated by new information that fits in the schema, in a necessary manner for learning (Tse et al. 2007; Tse et al. 2011). Recent studies in mice indicate a sustained role for hippocampus in the activation of neocortical circuits (Goshen et al. 2011) and in the recall of detailed memories (Wiltgen et al. 2010) at 2-4 weeks after memory storage. Overall, the anatomical and time-dependent reorganization of memory representations following their initial formation deserves intensive further study; $\mathrm{Ca}^{2+}$ imaging may allow a much richer set of observations regarding how schemas are established and impact the subsequent encoding of new information and the engagement of multiple brain areas. Other brain structures beyond hippocampus and neocortex also seem to undergo processes similar to systems consolidation (Repa et al. 2001; Do-Monte et al. 2015), indicating the general need for methods capable of revealing how the brain reorganizes memories over time.

\section{OUTLOOK}

The advent of powerful technologies for largescale $\mathrm{Ca}^{2+}$ imaging in behaving mammals has provided major new opportunities to study the ensemble neural dynamics that underlie learning and memory. We expect active advancements on multiple research fronts that will continue to improve the potency of $\mathrm{Ca}^{2+}$ imaging for such studies. Areas of technical progress will almost certainly include advances in new $\mathrm{Ca}^{2+}$ indicators (Fosque et al. 2015; Inoue et al. 2015), viral and genetic labeling methods (Oyibo et al. 2014; Madisen et al. 2015), optical instrumentation for imaging in one or more brain areas (Lecoq et al. 2014; Stirman et al. 2014), the combination of $\mathrm{Ca}^{2+}$ imaging and optogenetics (Grosenick et al. 2015), behavioral assays expressly designed or optimized for $\mathrm{Ca}^{2+}$-imaging studies (Lovett-Barron et al. 2014; Sofroniew et al. 2014), and computational analyses of large-scale neural-imaging data (Ziv et al. 2013; Peters et al. 2014). By combining such technologies, memory researchers will have unprecedented capabilities to decipher the ensemble neural codes that support longterm memory across a range of animal behaviors and brain areas, and to dissect the rules that govern memory storage. To bring the suite of available techniques to full fruition, collaborations between scientists with diverse expertise will become ever more crucial, as cutting-edge experiments increasingly require multidisciplinary knowledge in fields such as genetics, virology, cognitive and systems neuroscience, optics, and computer science. However, if the research community can effectively harness its collective know-how, we stand to gain important insights into long-standing questions about the organization of memory in the mammalian brain.

\section{ACKNOWLEDGMENTS}

We thank Alessio Attardo, Benjamin Grewe, Cristina Irimia, Margaret C. Larkin, Lacey J. Kitch, and Y. Ziv for helpful suggestions on the manuscript. M.J.S. acknowledges research support from NIBIB, NIDA, NINDS, NIMH, NSF, DARPA, and the Ellison Foundation. M.J.S. is a co-founder and consults scientifically for Inscopix, which has commercialized the miniature integrated microscope technology 
of Figure 3. P.J. is the recipient of a Marie Curie Fellowship.

\section{REFERENCES}

Aghajan ZM, Acharya L, Moore JJ, Cushman JD, Vuong C, Mehta MR. 2015. "Impaired spatial selectivity and intact phase precession in two-dimensional virtual reality." Nat Neurosci 18: 121-128.

Albright TD, Jessell TM, Kandel ER, Posner MI. 2000. “Neural science: A century of progress and the mysteries that remain. Neuron 25: S1-S55.

Alivisatos AP, Andrews AM, Boyden ES, Chun M, Church GM, Deisseroth K, Donoghue JP, Fraser SE, LippincottSchwartz J, Looger LL, et al. 2013. Nanotools for neuroscience and brain activity mapping. ACS Nano 7: 18501866.

Andermann ML, Kerlin AM, Reid RC. 2010. Chronic cellular imaging of mouse visual cortex during operant behavior and passive viewing. Front Cell Neurosci 4: 3 .

Andermann ML, Kerlin AM, Roumis DK, Glickfeld LL, Reid RC. 2011. Functional specialization of mouse higher visual cortical areas. Neuron 72: 1025-1039.

Aronov D, Tank DW. 2014. Engagement of neural circuits underlying $2 \mathrm{D}$ spatial navigation in a rodent virtual reality system. Neuron $\mathbf{8 4 :} 442-456$.

Aschauer DF, Kreuz S, Rumpel S. 2013. Analysis of transduction efficiency, tropism and axonal transport of AAV serotypes 1, 2, 5, 6, 8 and 9 in the mouse brain. PLoS ONE 8: e76310.

Attardo A, Fitzgerald JE, Schnitzer MJ. 2015. Impermanence of dendritic spines in live adult $\mathrm{CA} 1$ hippocampus. $\mathrm{Na}$ ture 523: 592-596.

Ballarini F, Moncada D, Martinez MC, Alen N, Viola H 2009. Behavioral tagging is a general mechanism of long-term memory formation. Proc Natl Acad Sci USA 106: 14599-14604.

Barretto RP, Ko TH, Jung JC, Wang TJ, Capps G, Waters AC, Ziv Y, Attardo A, Recht L, Schnitzer MJ. 2011. Time-lapse imaging of disease progression in deep brain areas using fluorescence microendoscopy. Nat Med 17: 223-228.

Bartlett FC. 1932. Remembering: A study in experimental and social psychology. Cambridge University Press, Cambridge.

Berdyyeva T, Otte S, Aluisio L, Ziv Y, Burns LD, Dugovic C, Yun S, Ghosh KK, Schnitzer MJ, Lovenberg T, et al. 2014. Zolpidem reduces hippocampal neuronal activity in freely behaving mice: A large scale calcium imaging study with miniaturized fluorescence microscope. PLOS ONE 9: e112068.

Betley JN, Xu S, Cao ZF, Gong R, Magnus CJ, Yu Y, Sternson SM. 2015. Neurons for hunger and thirst transmit a negative-valence teaching signal. Nature 521: 180185.

Blauvelt DG, Sato TF, Wienisch M, Knopfel T, Murthy VN. 2013. Distinct spatiotemporal activity in principal neurons of the mouse olfactory bulb in anesthetized and awake states. Front Neural Circuits 7: 46.

Bock DD, Lee WC, Kerlin AM, Andermann ML, Hood G, Wetzel AW, Yurgenson S, Soucy ER, Kim HS, Reid RC.
2011. Network anatomy and in vivo physiology of visual cortical neurons. Nature 471: 177-182.

Boender AJ, de Jong JW, Boekhoudt L, Luijendijk MC, Plasse Gvander, Adan RA. 2014. Combined use of the canine adenovirus-2 and DREADD-technology to activate specific neural pathways in vivo. PLOS ONE 9: e95392.

Bontempi B, Durkin TP. 2007. Memories: Molecules and circuits. In Dynamics of hippocampal-cortical interactions during memory consolidation: Insights from functional brain imaging, pp. 19-39. Springer, New York.

Bouchard MB, Voleti V, Mendes CS, Lacefield C, Grueber WB, Mann RS, Bruno RM, Hillman EM. 2015. Swept confocally-aligned planar excitation (SCAPE) microscopy for high speed volumetric imaging of behaving organisms. Nat Photonics 9: 113-119.

Bowers JS. 2009. On the biological plausibility of grandmother cells: Implications for neural network theories in psychology and neuroscience. Psychol Rev 116: 220 251.

Bru T, Salinas S, Kremer EJ. 2010. An update on canine adenovirus type 2 and its vectors. Viruses 2: 2134-2153.

Buzsaki G. 2005. Theta rhythm of navigation: Link between path integration and landmark navigation, episodic and semantic memory. Hippocampus 15: 827-840.

Buzsaki G, Moser EI. 2013. Memory, navigation and $\theta$ rhythm in the hippocampal-entorhinal system. Nat Neurosci 16: 130-138.

Card JP, Enquist LW. 2014. Transneuronal circuit analysis with pseudorabies viruses. Curr Protoc Neurosci doi: 10.1002/0471142301.ns0105s68.

Card JP, Kobiler O, McCambridge J, Ebdlahad S, Shan Z, Raizada MK, Sved AF, Enquist LW. 2011. Microdissection of neural networks by conditional reporter expression from a Brainbow herpesvirus. Proc Natl Acad Sci USA 108: $3377-3382$.

Carey RM, Verhagen JV, Wesson DW, Pírez N, Wachowiak M. 2009. Temporal structure of receptor neuron input to the olfactory bulb imaged in behaving rats. J Neurophysiol 101: 1073-1088.

Chen BE, Trachtenberg JT, Holtmaat AJ, Svoboda K. 2008. Long-term, high-resolution imaging in the neocortex in vivo. CSH Protoc 2008: pdb prot4902.

Chen JL, Villa KL, Cha JW, So PT, Kubota Y, Nedivi E. 2012a. Clustered dynamics of inhibitory synapses and dendritic spines in the adult neocortex. Neuron 74: 361-373.

Chen Q, Cichon J, Wang W, Qiu L, Lee SJ, Campbell NR, Destefino N, Goard MJ, Fu Z, Yasuda R, et al. 2012b. Imaging neural activity using Thyl-GCaMP transgenic mice. Neuron 76: 297-308.

Chen TW, Wardill TJ, Sun Y, Pulver SR, Renninger SL, Baohan A, Schreiter ER, Kerr RA, Orger MB, Jayaraman V, et al. 2013. Ultrasensitive fluorescent proteins for imaging neuronal activity. Nature 499: 295-300.

Choi GB, Stettler DD, Kallman BR, Bhaskar ST, Fleischmann A, Axel R. 2011. Driving opposing behaviors with ensembles of piriform neurons. Cell 146: $1004-$ 1015.

Chung K, Wallace J, Kim SY, Kalyanasundaram S, Andalman AS, Davidson TJ, Mirzabekov JJ, Zalocusky KA, Mattis J, Denisin AK, et al. 2013. Structural and molecular inter- 
P. Jercog et al.

rogation of intact biological systems. Nature 497: $332-$ 337.

Ciocchi S, Herry C, Grenier F, Wolff SB, Letzkus JJ, Vlachos I, Ehrlich I, Sprengel R, Deisseroth K, Stadler MB, et al. 2010. Encoding of conditioned fear in central amygdala inhibitory circuits. Nature 468: 277-282.

Cowansage KK, Shuman T, Dillingham BC, Chang A, Golshani P, Mayford M. 2014. Direct reactivation of a coherent neocortical memory of context. Neuron 84: 432-441.

Cruz-Martin A, Crespo M, Portera-Cailliau C. 2010. Delayed stabilization of dendritic spines in fragile $\mathrm{X}$ mice. J Neurosci 30: 7793-7803.

Czajkowski R, Jayaprakash B, Wiltgen B, Rogerson T, Guzman-Karlsson MC, Barth AL, Trachtenberg JT, Silva AJ. 2014. Encoding and storage of spatial information in the retrosplenial cortex. Proc Natl Acad Sci USA 111: 86618666.

Dana H, Chen TW, Hu A, Shields BC, Guo C, Looger LL, Kim DS, Svoboda K. 2014. Thyl-GCaMP6 transgenic mice for neuronal population imaging in vivo. PLoS ONE 9: e108697.

Date CJ. 2000. The database relational model: A retrospective review and analysis. Pearson, London.

Debiec J, Doyere V, Nader K, Ledoux JE. 2006. Directly reactivated, but not indirectly reactivated, memories undergo reconsolidation in the amygdala. Proc Natl Acad Sci USA 103: 3428-3433.

Deisseroth K, Schnitzer MJ. 2013. Engineering approaches to illuminating brain structure and dynamics. Neuron $\mathbf{8 0}$ 568-577.

Dombeck DA, Harvey CD, Tian L, Looger LL, Tank DW. 2010. Functional imaging of hippocampal place cells at cellular resolution during virtual navigation. Nat Neurosci 13: 1433-1440.

Dombeck DA, Khabbaz AN, Collman F, Adelman TL, Tank DW. 2007. Imaging large-scale neural activity with cellular resolution in awake, mobile mice. Neuron 56: 43-57.

Do-Monte FH, Quinones-Laracuente K, Quirk GJ. 2015. A temporal shift in the circuits mediating retrieval of fear memory. Nature 519: 460-463.

Dudai Y. 2004. The neurobiology of consolidations, or, how stable is the engram? Annu Rev Psychol 55: 51-86.

Eichenbaum H. 2000. A cortical-hippocampal system for declarative memory. Nat Rev Neurosci 1: 41-50.

El-Boustani S, Sur M. 2014. Response-dependent dynamics of cell-specific inhibition in cortical networks in vivo. Nat Commun 5: 5689.

Enquist LW, Tomishima MJ, Gross S, Smith GA. 2002. Directional spread of an $\alpha$-herpesvirus in the nervous system. Vet Microbiol 86: 5-16.

Etessami R, Conzelmann KK, Fadai-Ghotbi B, Natelson B, Tsiang H, Ceccaldi PE. 2000. Spread and pathogenic characteristics of a G-deficient rabies virus recombinant: An in vitro and in vivo study. J Gen Virol 81: 2147-2153.

Flusberg BA, Nimmerjahn A, Cocker ED, Mukamel EA, Barretto RP, Ko TH, Burns LD, Jung JC, Schnitzer MJ. 2008. High-speed, miniaturized fluorescence microscopy in freely moving mice. Nat Methods 5: 935-938.

Fosque BF, Sun Y, Dana H, Yang CT, Ohyama T, Tadross MR, Patel R, Zlatic M, Kim DS, Ahrens MB, et al. 2015. Neural circuits. Labeling of active neural circuits in vivo with designed calcium integrators. Science 347: 755-760.

Frankland PW, Bontempi B. 2005. The organization of recent and remote memories. Nat Rev Neurosci 6: 119-130.

Frey U, Morris RG. 1997. Synaptic tagging and long-term potentiation. Nature 385: 533-536.

Fu M, Yu X, Lu J, Zuo Y. 2012. Repetitive motor learning induces coordinated formation of clustered dendritic spines in vivo. Nature 483: 92-95.

Fuster JM. 2009. Cortex and memory: Emergence of a new paradigm. J Cogn Neurosci 21: 2047-2072.

Garaschuk O, Milos RI, Konnerth A. 2006. Targeted bulkloading of fluorescent indicators for two-photon brain imaging in vivo. Nat Protoc 1: 380-386.

Garner AR, Rowland DC, Hwang SY, Baumgaertel K, Roth BL, Kentros C, Mayford M. 2012. Generation of a synthetic memory trace. Science 335: 1513-1516.

Gewirtz JC, Davis M. 2000. Using pavlovian higher-order conditioning paradigms to investigate the neural substrates of emotional learning and memory. Learn Mem 7: 257-266.

Ghosh KK, Burns LD, Cocker ED, Nimmerjahn A, Ziv Y, Gamal AE, Schnitzer MJ. 2011. Miniaturized integration of a fluorescence microscope. Nat Methods 8: 871-878.

Glickfeld LL, Andermann ML, Bonin V, Reid RC. 2013. Cortico-cortical projections in mouse visual cortex are functionally target specific. Nat Neurosci 16: 219-226.

Goshen I, Brodsky M, Prakash R, Wallace J, Gradinaru V, Ramakrishnan C, Deisseroth K. 2011. Dynamics of retrieval strategies for remote memories. Cell 147: 678689.

Grewe BF, Lecoq J, Kitch L, Li J, Marshall J, Venkataraman G, Grundemann J, Luthi A, Schnitzer MJ. 2014. Calcium imaging of stimulus specific neuronal responses in the lateral amygdala during fear learning. Society for Neuroscience, Washington, DC.

Grienberger C, Konnerth A. 2012. Imaging calcium in neurons. Neuron 73: 862-885.

Grosenick L, Marshel JH, Deisseroth K. 2015. Closed-loop and activity-guided optogenetic control. Neuron 86: 106-139.

Grutzendler J, Kasthuri N, Gan WB. 2002. Long-term dendritic spine stability in the adult cortex. Nature 420: $812-$ 816.

Guenthner CJ, Miyamichi K, Yang HH, Heller HC, Luo L. 2013. Permanent genetic access to transiently active neurons via TRAP: Targeted recombination in active populations. Neuron 78: 773-784.

Guzowski JF, McNaughton BL, Barnes CA, Worley PF. 1999. Environment-specific expression of the immediate-early gene Arc in hippocampal neuronal ensembles. Nat Neurosci 2: $1120-1124$.

Guzowski JF, Worley PF. 2001. Cellular compartment analysis of temporal activity by fluorescence in situ hybridization (catFISH). Curr Protoc Neurosci doi: 10.1002/ 0471142301.ns0108s15.

Hama H, Kurokawa H, Kawano H, Ando R, Shimogori T, Noda H, Fukami K, Sakaue-Sawano A, Miyawaki A. 2011. Scale: A chemical approach for fluorescence imaging and reconstruction of transparent mouse brain. Nat Neurosci 14: $1481-1488$. 
Hamel EJ, Grewe BF, Parker JG, Schnitzer MJ. 2015. Cellular level brain imaging in behaving mammals: An engineering approach. Neuron 86: 140-159.

Han JH, Kushner SA, Yiu AP, Cole CJ, Matynia A, Brown RA, Neve RL, Guzowski JF, Silva AJ, Josselyn SA. 2007. Neuronal competition and selection during memory formation. Science 316: 457-460.

Han JH, Kushner SA, Yiu AP, Hsiang HL, Buch T, Waisman A, Bontempi B, Neve RL, Frankland PW, Josselyn SA. 2009. Selective erasure of a fear memory. Science 323: 1492-1496.

Harvey CD, Collman F, Dombeck DA, Tank DW. 2009. Intracellular dynamics of hippocampal place cells during virtual navigation. Nature 461: 941-946.

Harvey CD, Coen P, Tank DW. 2012. Choice-specific sequences in parietal cortex during a virtual-navigation decision task. Nature 484: 62-68.

Helmchen F, Imoto K, Sakmann B. 1996. $\mathrm{Ca}^{2+}$ buffering and action potential-evoked $\mathrm{Ca}^{2+}$ signaling in dendrites of pyramidal neurons. Biophys J 70: 1069-1081.

Helmchen F, Fee MS, Tank DW, Denk W. 2001. A miniature head-mounted two-photon microscope. High-resolution brain imaging in freely moving animals. Neuron 31: 903-912.

Heys JG, Rangarajan KV, Dombeck DA. 2014. The functional micro-organization of grid cells revealed by cellularresolution imaging. Neuron 84: 1079-1090.

Hnasko TS, Perez FA, Scouras AD, Stoll EA, Gale SD, Luquet S, Phillips PE, Kremer EJ, Palmiter RD. 2006. Cre recombinase-mediated restoration of nigrostriatal dopamine in dopamine-deficient mice reverses hypophagia and bradykinesia. Proc Natl Acad Sci USA 103: 8858-8863.

Holscher C, Schnee A, Dahmen H, Setia L, Mallot HA. 2005. Rats are able to navigate in virtual environments. J Exp Biol 208: $561-569$.

Holtmaat A, Bonhoeffer T, Chow DK, Chuckowree J, De Paola V, Hofer SB, Hubener M, Keck T, Knott G, Lee WC, et al. 2009. Long-term, high-resolution imaging in the mouse neocortex through a chronic cranial window. Nat Protoc 4: 1128-1144.

Hoover JE, Strick PL. 1999. The organization of cerebellar and basal ganglia outputs to primary motor cortex as revealed by retrograde transneuronal transport of herpes simplex virus type 1. J Neurosci 19: 1446-1463.

Horton NG, Wang K, Kobat D, Clark CG, Wise FW, Schaffer CB, Xu C. 2013. In vivo three-photon microscopy of subcortical structures within an intact mouse brain. Nat Photonics 7: 205-209.

Huber D, Gutnisky DA, Peron S, O'Connor DH, Wiegert JS, Tian L, Oertner TG, Looger LL, Svoboda K. 2012. Multiple dynamic representations in the motor cortex during sensorimotor learning. Nature 484: 473-478.

Inoue $\mathrm{M}$, Takeuchi A, Horigane S, Ohkura M, GengyoAndo K, Fujii H, Kamijo S, Takemoto-Kimura S, Kano M, Nakai J, et al. 2015. Rational design of a high-affinity, fast, red calcium indicator R-CaMP2. Nat Methods 12: 64-70.

Jennings JH, Ung RL, Resendez SL, Stamatakis AM, Taylor JG, Huang J, Veleta K, Kantak PA, Aita M, Shilling-Scrivo $\mathrm{K}$, et al. 2015. Visualizing hypothalamic network dynam- ics for appetitive and consummatory behaviors. Cell 160: 516-527.

Johansen JP, Hamanaka H, Monfils MH, Behnia R, Deisseroth K, Blair HT, LeDoux JE. 2010. Optical activation of lateral amygdala pyramidal cells instructs associative fear learning. Proc Natl Acad Sci USA 107: 12692-12697.

Jorgenson LA, Newsome WT, Anderson DJ, Bargmann CI, Brown EN, Deisseroth K, Donoghue JP, Hudson KL, Ling GS, MacLeish PR, et al. 2015. The BRAIN Initiative: Developing technology to catalyse neuroscience discovery. Philos Trans R Soc Lond B Biol Sci 370: 20140164.

Jung JC, Schnitzer MJ. 2003. Multiphoton endoscopy. Opt Lett 28: 902-904.

Jung JC, Mehta AD, Aksay E, Stepnoski R, Schnitzer MJ. 2004. In vivo mammalian brain imaging using oneand two-photon fluorescence microendoscopy. J Neurophysiol 92: 3121-3133.

Kaifosh P, Lovett-Barron M, Turi GF, Reardon TR, Losonczy A. 2013. Septo-hippocampal GABAergic signaling across multiple modalities in awake mice. Nat Neurosci 16: $1182-1184$.

Kawashima T, Kitamura K, Suzuki K, Nonaka M, Kamijo S, Takemoto-Kimura S, Kano M, Okuno H, Ohki K, Bito H. 2013. Functional labeling of neurons and their projections using the synthetic activity-dependent promoter E-SARE. Nat Methods 10: 889-895.

Ke MT, Fujimoto S, Imai T. 2013. SeeDB: A simple and morphology-preserving optical clearing agent for neuronal circuit reconstruction. Nat Neurosci 16: 1154-1161.

Keller GB, Bonhoeffer T, Hubener M. 2012. Sensorimotor mismatch signals in primary visual cortex of the behaving mouse. Neuron 74: 809-815.

Kelly RM, Strick PL. 2000. Rabies as a transneuronal tracer of circuits in the central nervous system. J Neurosci Methods 103: 63-71.

Kentros CG, Agnihotri NT, Streater S, Hawkins RD, Kandel ER. 2004. Increased attention to spatial context increases both place field stability and spatial memory. Neuron 42: 283-295.

Kerlin AM, Andermann ML, Berezovskii VK, Reid RC. 2010. Broadly tuned response properties of diverse inhibitory neuron subtypes in mouse visual cortex. Neuron 67: $858-871$.

Kim JJ, Fanselow MS. 1992. Modality-specific retrograde amnesia of fear. Science 256: 675-677.

Kim J, Kwon JT, Kim HS, Josselyn SA, Han JH. 2014. Memory recall and modifications by activating neurons with elevated CREB. Nat Neurosci 17: 65-72.

Kimpo RR, Rinaldi JM, Kim CK, Payne HL, Raymond JL. 2014. Gating of neural error signals during motor learning. eLife 3: $\mathrm{e} 02076$.

Komiyama T, Sato TR, O'Connor DH, Zhang Y-X, Huber D, Hooks BM, Gabitto M, Svoboda K. 2010. Learning-related fine-scale specificity imaged in motor cortex circuits of behaving mice. Nature 464: 1182-1186.

Komiyama T, Sato TR, O'Connor DH, Zhang YX, Huber D, Hooks BM, Gabitto M, Svoboda K. 2010. Learning-related fine-scale specificity imaged in motor cortex circuits of behaving mice. Nature 464: 1182-1186.

Kwon JT, Nakajima R, Kim HS, Jeong Y, Augustine GJ, Han JH. 2014. Optogenetic activation of presynaptic inputs in 
P. Jercog et al.

lateral amygdala forms associative fear memory. Learn Mem 21: 627-633.

Lai CS, Franke TF, Gan WB. 2012. Opposite effects of fear conditioning and extinction on dendritic spine remodelling. Nature 483: 87-91.

Laubach M, Wessberg J, Nicolelis MAL. 2000. Cortical ensemble activity increasingly predicts behaviour outcomes during learning of a motor task. Nature 405: 567-571.

Lecoq J, Savall J, Vucinic D, Grewe BF, Kim H, Li JZ, Kitch LJ, Schnitzer MJ. 2014. Visualizing mammalian brain area interactions by dual-axis two-photon calcium imaging. Nat Neurosci 17: 1825-1829.

Lee AK, Manns ID, Sakmann B, Brecht M. 2006. Whole-cell recordings in freely moving rats. Neuron 51: 399-407.

Lefort S, O'Connor EC, Luscher C. 2014. In vivo calcium imaging of nucleus accumbens neurons in freely feeding mice. Society for Neuroscience, Washington, DC.

Letzkus JJ, Wolff SB, Meyer EM, Tovote P, Courtin J, Herry C, Luthi A. 2011. A disinhibitory microcircuit for associative fear learning in the auditory cortex. Nature 480: 331-335.

Leutgeb S, Leutgeb JK, Barnes CA, Moser EI, McNaughton BL, Moser MB. 2005. Independent codes for spatial and episodic memory in hippocampal neuronal ensembles. Science 309: 619-623.

Levene MJ, Dombeck DA, Kasischke KA, Molloy RP, Webb WW. 2004. In vivo multiphoton microscopy of deep brain tissue. J Neurophysiol 91: 1908-1912.

Lever C, Wills T, Cacucci F, Burgess N, O'Keefe J. 2002. Long-term plasticity in hippocampal place-cell representation of environmental geometry. Nature 416: 90-94.

Liu X, Ramirez S, Pang PT, Puryear CB, Govindarajan A, Deisseroth K, Tonegawa S. 2012. Optogenetic stimulation of a hippocampal engram activates fear memory recall. Nature 484: 381-385.

Lo L, Anderson DJ. 2011. A Cre-dependent, anterograde transsynaptic viral tracer for mapping output pathways of genetically marked neurons. Neuron 72: 938-950.

Looger LL, Griesbeck O. 2012. Genetically encoded neural activity indicators. Curr Opin Neurobiol 22: 18-23.

Lovett-Barron M, Kaifosh P, Kheirbek MA, Danielson N, Zaremba JD, Reardon TR, Turi GF, Hen R, Zemelman BV, Losonczy A. 2014. Dendritic inhibition in the hippocampus supports fear learning. Science 343: 857-863.

Low RJ, Gu Y, Tank DW. 2014. Cellular resolution optical access to brain regions in fissures: Imaging medial prefrontal cortex and grid cells in entorhinal cortex. Proc Natl Acad Sci USA 111: 18739-18744.

Lutcke H, Margolis DJ, Helmchen F. 2013. Steady or changing? Long-term monitoring of neuronal population activity. Trends Neurosci 36: 375-384.

Madisen L, Zwingman TA, Sunkin SM, Oh SW, Zariwala HA, Gu H, Ng LL, Palmiter RD, Hawrylycz MJ, Jones AR, et al. 2010. "A robust and high-throughput Cre reporting and characterization system for the whole mouse brain." Nat Neurosci 13: 133-140.

Madisen L, Garner AR, Shimaoka D, Chuong AS, Klapoetke NC, Li L, Bourg Avander, Niino Y, Egolf L, Monetti C, et al. 2015. Transgenic mice for intersectional targeting of neural sensors and effectors with high specificity and performance. Neuron 85: 942-958.
Mank M, Santos AF, Direnberger S, Mrsic-Flogel TD, Hofer SB, Stein V, Hendel T, Reiff DF, Levelt C, Borst A, et al. 2008. A genetically encoded calcium indicator for chronic in vivo two-photon imaging. Nat Methods 5: 805-811.

Mankin EA, Sparks FT, Slayyeh B, Sutherland RJ, Leutgeb S, Leutgeb JK. 2012. Neuronal code for extended time in the hippocampus. Proc Natl Acad Sci USA 109: 19462 19467.

Margrie TW, Brecht M, Sakmann B. 2002. In vivo, low-resistance, whole-cell recordings from neurons in the anaesthetized and awake mammalian brain. Pflugers Arch-Eur J Physiol 444: 491-498.

Masamizu Y, Tanaka YR, Tanaka YH, Hira R, Ohkubo F, Kitamura K, Isomura Y, Okada T, Matsuzaki M. 2014. Two distinct layer-specific dynamics of cortical ensembles during learning of a motor task. Nat Neurosci 17: 987-994.

Masson JME. 1987. A distributed memory model of context effects in word identification. Bull Psychon Soc 25: 335335.

McClelland JL, McNaughton BL, O'Reilly RC. 1995. Why there are complementary learning systems in the hippocampus and neocortex: Insights from the successes and failures of connectionist models of learning and memory. Psychol Rev 102: 419-457.

McHugh TJ, Blum KI, Tsien JZ, Tonegawa S, Wilson MA. 1996. Impaired hippocampal representation of space in CA1-specific NMDAR1 knockout mice. Cell 87: 1339_ 1349.

McKenzie S, Robinson NT, Herrera L, Churchill JC, Eichenbaum H. 2013. "Learning causes reorganization of neuronal firing patterns to represent related experiences within a hippocampal schema." J Neurosci 33: $10243-$ 10256.

McKenzie S, Frank AJ, Kinsky NR, Porter B, Riviere PD, Eichenbaum H. 2014. Hippocampal representation of related and opposing memories develop within distinct, hierarchically organized neural schemas. Neuron 83: 202-215.

Miller JE, Ayzenshtat I, Carrillo-Reid L, Yuste R. 2014. Visual stimuli recruit intrinsically generated cortical ensembles. Proc Natl Acad Sci USA 111: E4053-E4061.

Miyamichi K, Amat F, Moussavi F, Wang C, Wickersham I, Wall NR, Taniguchi H, Tasic B, Huang ZJ, He Z, et al. 2011. Cortical representations of olfactory input by trans-synaptic tracing. Nature 472: 191-196.

Modi MN, Dhawale AK, Bhalla US. 2014. CA1 cell activity sequences emerge after reorganization of network correlation structure during associative learning. eLife 3: e01982.

Moncada D, Viola H. 2007. Induction of long-term memory by exposure to novelty requires protein synthesis: Evidence for a behavioral tagging. J Neurosci 27: 7476-7481.

Mostany R, Anstey JE, Crump KL, Maco B, Knott G, Portera-Cailliau C. 2013. Altered synaptic dynamics during normal brain aging. J Neurosci 33: 4094-4104.

Muller RU, Kubie JL, Ranck JB Jr, 1987. Spatial firing patterns of hippocampal complex-spike cells in a fixed environment. J Neurosci 7: 1935-1950.

Muzzio IA, Levita L, Kulkarni J, Monaco J, Kentros C, Stead M, Abbott LF, Kandel ER. 2009. Attention enhances the 
retrieval and stability of visuospatial and olfactory representations in the dorsal hippocampus. PLoS Biol 7: e1000140.

Nakazawa K, Sun LD, Quirk MC, Rondi-Reig L, Wilson MA, Tonegawa S. 2003. Hippocampal CA3 NMDA receptors are crucial for memory acquisition of one-time experience. Neuron 38: 305-315.

Nguyen-Vu TD, Kimpo RR, Rinaldi JM, Kohli A, Zeng H, Deisseroth K, Raymond JL. 2013. Cerebellar Purkinje cell activity drives motor learning. Nat Neurosci 16: $1734-$ 1736.

Nimmerjahn A, Mukamel EA, Schnitzer MJ. 2009. Motor behavior activates Bergmann glial networks. Neuron 62: $400-412$.

O'Connor DH, Peron SP, Huber D, Svoboda K. 2010. Neural activity in barrel cortex underlying vibrissa-based object localization in mice. Neuron 67: 1048-1061.

Osakada F, Callaway EM. 2013. Design and generation of recombinant rabies virus vectors. Nat Protoc 8: 15831601.

Osakada F, Mori T, Cetin AH, Marshel JH, Virgen B, Callaway EM. 2011. New rabies virus variants for monitoring and manipulating activity and gene expression in defined neural circuits. Neuron 71: 617-631.

Oyibo HK, Znamenskiy P, Oviedo HV, Enquist LW, Zador AM. 2014. Long-term Cre-mediated retrograde tagging of neurons using a novel recombinant pseudorabies virus. Front Neuroanat 8: 86.

Packer AM, Peterka DS, Hirtz JJ, Prakash R, Deisseroth K, Yuste R. 2012. Two-photon optogenetics of dendritic spines and neural circuits. Nat Methods 9: 1202-1205.

Packer AM, Russell LE, Dalgleish HW, Hausser M. 2015. Simultaneous all-optical manipulation and recording of neural circuit activity with cellular resolution in vivo. Nat Methods 12: 140-146.

Page M. 2000. "Connectionist modelling in psychology: A localist manifesto. Behav Brain Sci 23: 443-467; discussion 467-512.

Parker JG, Marshall JD, Ahanonu B, Grewe B, J Zhong LI, Ehlers MD, J MJSM. 2014. Parallel remodeling of direct and indirect pathway neuronal activity in the nucleus accumbens during Pavlovian reward conditioning. Society for Neuroscience, Washington, DC.

Patterson MA, Lagier S, Carleton A. 2013. Odor representations in the olfactory bulb evolve after the first breath and persist as an odor afterimage. Proc Natl Acad Sci USA 110: E3340-E3349.

Peters AJ, Chen SX, Komiyama T. 2014. Emergence of reproducible spatiotemporal activity during motor learning. Nature 510: 263-267.

Petreanu L, Gutnisky DA, Huber D, Xu N-1, O’Connor DH, Tian L, Looger L, Svoboda K. 2012. Activity in motorsensory projections reveals distributed coding in somatosensation. Nature 489: 299-303.

Piaget J, Tomlinson J, Tomlinson A. 1929. The child's conception of the world. Rowman \& Littlefield, Lanham, MD.

Pine DS, Grun J, Maguire EA, Burgess N, Zarahn E, Koda V, Fyer A, Szeszko PR, Bilder RM. 2002. Neurodevelopmental aspects of spatial navigation: A virtual reality fMRI study. Neuroimage 15: 396-406.
Plaut DC, McClelland JL. 2010. Locating object knowledge in the brain: Comment on Bowers's (2009) attempt to revive the grandmother cell hypothesis. Psychol Rev 117: 284-288.

Prakash R, Yizhar O, Grewe B, Ramakrishnan C, Wang N, Goshen I, Packer AM, Peterka DS, Yuste R, Schnitzer MJ, et al. 2012. Two-photon optogenetic toolbox for fast inhibition, excitation and bistable modulation. Nat Methods 9: 1171-1179.

Preston AR, Eichenbaum H. 2013. Interplay of hippocampus and prefrontal cortex in memory. Curr Biol 23: R764-R773.

Quian Quiroga R, Kreiman G. 2010. Measuring sparseness in the brain: Comment on Bowers (2009). Psychol Rev 117: 291-297.

Quirin S, Jackson J, Peterka DS, Yuste R. 2014. Simultaneous imaging of neural activity in three dimensions. Front Neural Circuits 8: 29.

Ramirez S, Liu X, Lin PA, Suh J, Pignatelli M, Redondo RL, Ryan TJ, Tonegawa S. 2013. Creating a false memory in the hippocampus. Science 341: 387-391.

Ravassard P, Kees A, Willers B, Ho D, Aharoni D, Cushman J, Aghajan ZM, Mehta MR. 2013. Multisensory control of hippocampal spatiotemporal selectivity. Science 340: 1342-1346.

Redondo RL, Kim J, Arons AL, Ramirez S, Liu X, Tonegawa S. 2014. Bidirectional switch of the valence associated with a hippocampal contextual memory engram. Nature 513: $426-430$.

Reijmers LG, Perkins BL, Matsuo N, Mayford M. 2007. Localization of a stable neural correlate of associative memory. Science 317: 1230-1233.

Repa JC, Muller J, Apergis J, Desrochers TM, Zhou Y, LeDoux JE. 2001. Two different lateral amygdala cell populations contribute to the initiation and storage of memory. Nat Neurosci 4: 724-731.

Rickgauer JP, Deisseroth K, Tank DW. 2014. Simultaneous cellular-resolution optical perturbation and imaging of place cell firing fields. Nat Neurosci 17: 1816-1824.

Rogerson T, Cai DJ, Frank A, Sano Y, Shobe J, Lopez-Aranda MF, Silva AJ. 2014. Synaptic tagging during memory allocation. Nat Rev Neurosci 15: 157-169.

Rotenberg A, Mayford M, Hawkins RD, Kandel ER, Muller RU. 1996. Mice expressing activated CaMKII lack low frequency LTP and do not form stable place cells in the CA1 region of the hippocampus. Cell 87: 1351-1361.

Rumelhart DE, McClelland JL; Group University of California San Diego PDP Research. 1986. Parallel distributed processing explorations in the microstructure of cognition, Vol. 1, Foundations. In Computational models of cognition and perception. MIT Press, Cambridge, MA.

Runyan CA, Schummers J, Van Wart A, Kuhlman SJ, Wilson NR, Huang ZJ, Sur M. 2010. Response features of parvalbumin-expressing interneurons suggest precise roles for subtypes of inhibition in visual cortex. Neuron 67: 847857.

Sadtler PT, Quick KM, Golub MD, Chase SM, Ryu SI, TylerKabara EC, Yu BM, Batista AP. 2014. Neural constraints on learning. Nature 512: 423-426.

Sauer B. 1998. Inducible gene targeting in mice using the Cre/lox system. Methods 14: 381-392. 
P. Jercog et al.

Sawinski J, Wallace DJ, Greenberg DS, Grossmann S, Denk W, Kerr JN. 2009. Visually evoked activity in cortical cells imaged in freely moving animals. Proc Natl Acad Sci USA 106: $19557-19562$.

Scoville WB, Milner B. 1957. Loss of recent memory after bilateral hippocampal lesions. J Neurol Neurosurg Psychiatry 20: $11-21$.

Senn V, Wolff SB, Herry C, Grenier F, Ehrlich I, Grundemann J, Fadok JP, Muller C, Letzkus JJ, Luthi A. 2014 Long-range connectivity defines behavioral specificity of amygdala neurons. Neuron 81: 428-437.

Sheffield ME, Dombeck DA. 2015. Calcium transient prevalence across the dendritic arbour predicts place field properties. Nature 517: 200-204.

Silva AJ, Zhou Y, Rogerson T, Shobe J, Balaji J. 2009. Molecular and cellular approaches to memory allocation in neural circuits. Science 326: 391-395.

Sofroniew NJ, Cohen JD, Lee AK, Svoboda K. 2014. Natural whisker-guided behavior by head-fixed mice in tactile virtual reality. J Neurosci 34: 9537-9550.

Squire LR, Alvarez P. 1995. Retrograde amnesia and memory consolidation: A neurobiological perspective. Curr Opin Neurobiol 5: 169-177.

Stirman JN, Smith IT, Kudenov MW, Smith SL. 2014. Wide field-of-view, twin-region two-photon imaging across extended cortical networks. bioRxiv doi: 10.1101/ 011320.

Sun XR, Badura A, Pacheco DA, Lynch LA, Schneider ER, Taylor MP, Hogue IB, Enquist LW, Murthy M, Wang SS. 2013. Fast GCaMPs for improved tracking of neuronal activity. Nat Commun 4: 2170.

Susaki EA, Tainaka K, Perrin D, Kishino F, Tawara T, Watanabe TM, Yokoyama C, Onoe H, Eguchi M, Yamaguchi S, et al. 2014. Whole-brain imaging with single-cell resolution using chemical cocktails and computational analysis. Cell 157: 726-739.

Suthana N, Haneef Z, Stern J, Mukamel R, Behnke E, Knowlton B, Fried I. 2012. Memory enhancement and deep-brain stimulation of the entorhinal area. $N$ Engl J Med 366: 502-510.

Szabo V, Ventalon C, De Sars V, Bradley J, Emiliani V. 2014. Spatially selective holographic photoactivation and functional fluorescence imaging in freely behaving mice with a fiberscope. Neuron 84: 1157-1169.

Taber KH, Strick PL, Hurley RA. 2005. Rabies and the cerebellum: New methods for tracing circuits in the brain. $J$ Neuropsychiatry Clin Neurosci 17: 133-139.

Thompson LT, Best PJ. 1990. Long-term stability of the place-field activity of single units recorded from the dorsal hippocampus of freely behaving rats. Brain Res 509: 299-308.

Tian L, Hires SA, Mao T, Huber D, Chiappe ME, Chalasani SH, Petreanu L, Akerboom J, McKinney SA, Schreiter ER, et al. 2009. Imaging neural activity in worms, flies and mice with improved GCaMP calcium indicators. Nat Methods 6: 875-881.

Tian L, Akerboom J, Schreiter ER, Looger LL. 2012. Neural activity imaging with genetically encoded calcium indicators. Prog Brain Res 196: 79-94.

Trachtenberg JT, Chen BE, Knott GW, Feng G, Sanes JR, Welker E, Svoboda K. 2002. Long-term in vivo imaging of experience-dependent synaptic plasticity in adult cortex. Nature 420: 788-794.

Trimmer JS, Rhodes KJ. 2004. Localization of voltage-gated ion channels in mammalian brain. Annu Rev Physiol 66: 477-519.

Tse D, Langston RF, Kakeyama M, Bethus I, Spooner PA, Wood ER, Witter MP, Morris RG. 2007. Schemas and memory consolidation. Science 316: 76-82.

Tse D, Takeuchi T, Kakeyama M, Kajii Y, Okuno H, Tohyama C, Bito H, Morris RG. 2011. Schema-dependent gene activation and memory encoding in neocortex. Science 333: $891-895$.

van Kesteren MT, Ruiter DJ, Fernandez G, Henson RN. 2012. How schema and novelty augment memory formation. Trends Neurosci 35: 211-219.

Verhagen JV, Wesson DW, Netoff TI, White JA, Wachowiak M. 2007. Sniffing controls an adaptive filter of sensory input to the olfactory bulb. Nat Neurosci 10: 631-639.

Wickersham IR, Finke S, Conzelmann KK, Callaway EM. 2007a. Retrograde neuronal tracing with a deletion-mutant rabies virus. Nat Methods 4: 47-49.

Wickersham IR, Lyon DC, Barnard RJ, Mori T, Finke S, Conzelmann KK, Young JA, Callaway EM. 2007b. Monosynaptic restriction of transsynaptic tracing from single, genetically targeted neurons. Neuron 53: 639-647.

Wilt BA, Fitzgerald JE, Schnitzer MJ. 2013. Photon shot noise limits on optical detection of neuronal spikes and estimation of spike timing. Biophys J 104: 51-62.

Wiltgen BJ, Brown RA, Talton LE, Silva AJ. 2004. New circuits for old memories: the role of the neocortex in consolidation. Neuron 44: 101-108.

Wiltgen BJ, Zhou M, Cai Y, Balaji J, Karlsson MG, Parivash SN, Li W, Silva AJ. 2010. The hippocampus plays a selective role in the retrieval of detailed contextual memories. Curr Biol 20: 1336-1344.

Wolff SB, Grundemann J, Tovote P, Krabbe S, Jacobson GA, Muller C, Herry C, Ehrlich I, Friedrich RW, Letzkus JJ, et al. 2014. Amygdala interneuron subtypes control fear learning through disinhibition. Nature 509: 453-458.

Xu N-1, Harnett MT, Williams SR, Huber D, O'Connor DH, Svoboda K, Magee JC. 2012. Nonlinear dendritic integration of sensory and motor input during an active sensing task. Nature 492: 247-251.

Yang G, Pan F, Gan WB. 2009. Stably maintained dendritic spines are associated with lifelong memories. Nature 462: 920-924.

Yang B, Treweek JB, Kulkarni RP, Deverman BE, Chen CK, Lubeck E, Shah S, Cai L, Gradinaru V. 2014a. Single-cell phenotyping within transparent intact tissue through whole-body clearing. Cell 158: 945-958.

Yang G, Lai CS, Cichon J, Ma L, Li W, Gan WB. 2014b. Sleep promotes branch-specific formation of dendritic spines after learning. Science 344: 1173-1178.

Yiu AP, Mercaldo V, Yan C, Richards B, Rashid AJ, Hsiang HL, Pressey J, Mahadevan V, Tran MM, Kushner SA, et al. 2014. Neurons are recruited to a memory trace based on relative neuronal excitability immediately before training. Neuron 83: 722-735.

Zariwala HA, Borghuis BG, Hoogland TM, Madisen L, Tian L, De Zeeuw CI, Zeng H, Looger LL, Svoboda K, Chen 
Fluorescence Calcium Imaging for Long-Term Memory Studies in Mammals

TW. 2012. ACre-dependent GCaMP3 reporter mouse for neuronal imaging in vivo. J Neurosci 32: 3131-3141.

Zhou Y, Won J, Karlsson MG, Zhou M, Rogerson T, Balaji J, Neve R, Poirazi P, Silva AJ. 2009. CREB regulates excitability and the allocation of memory to subsets of neurons in the amygdala. Nat Neurosci 12: 1438 1443.
Ziv Y, Burns LD, Cocker ED, Hamel EO, Ghosh KK, Kitch LJ, Gamal AEl, Schnitzer MJ. 2013. Long-term dynamics of CA1 hippocampal place codes. Nat Neurosci 16: $264-$ 266.

Zuo Y, Yang G, Kwon E, Gan WB. 2005. Long-term sensory deprivation prevents dendritic spine loss in primary somatosensory cortex. Nature 436: 261-265. 


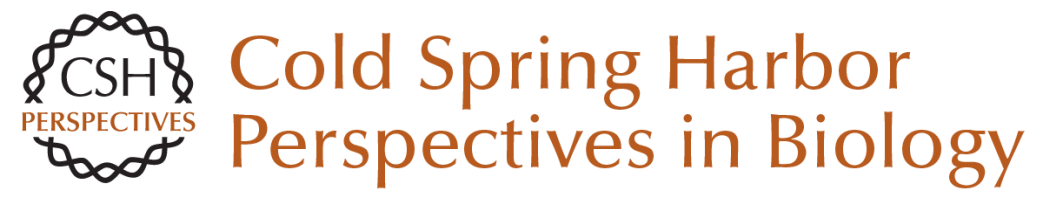

\section{Large-Scale Fluorescence Calcium-Imaging Methods for Studies of Long-Term Memory in Behaving Mammals}

Pablo Jercog, Thomas Rogerson and Mark J. Schnitzer

Cold Spring Harb Perspect Biol 2016; doi: 10.1101/cshperspect.a021824 originally published online April 5, 2016

Subject Collection Learning and Memory

Large-Scale Fluorescence Calcium-Imaging

Methods for Studies of Long-Term Memory in

Behaving Mammals

Pablo Jercog, Thomas Rogerson and Mark J. Schnitzer

Exploring Memory Representations with

Activity-Based Genetics

Mark Mayford and Leon Reijmers

The Origins and Organization of Vertebrate

Pavlovian Conditioning Michael S. Fanselow and Kate M. Wassum

The Corticohippocampal Circuit, Synaptic

Plasticity, and Memory

Jayeeta Basu and Steven A. Siegelbaum

Motor Learning and the Cerebellum

Chris I. De Zeeuw and Michiel M. Ten Brinke

The Striatum: Where Skills and Habits Meet Ann M. Graybiel and Scott T. Grafton

Molecular Genetic Strategies in the Study of Corticohippocampal Circuits

Christopher C. Angelakos and Ted Abel

Nonassociative Learning in Invertebrates John H. Byrne and Robert D. Hawkins
The Role of Functional Prion-Like Proteins in the

Persistence of Memory

Kausik Si and Eric R. Kandel

Working Memory: Maintenance, Updating, and the Realization of Intentions

Lars Nyberg and Johan Eriksson

Memory Retrieval in Mice and Men

Aya Ben-Yakov, Yadin Dudai and Mark R. Mayford

Reconsolidation and the Dynamic Nature of

Memory

Karim Nader

Memory Consolidation

Larry R. Squire, Lisa Genzel, John T. Wixted, et al.

Structural Components of Synaptic Plasticity and Memory Consolidation

Craig H. Bailey, Eric R. Kandel and Kristen M. Harris

Associative Learning in Invertebrates

Robert D. Hawkins and John H. Byrne

The Regulation of Transcription in Memory

Consolidation

Cristina M. Alberini and Eric R. Kandel

For additional articles in this collection, see http://cshperspectives.cshlp.org/cgi/collection/

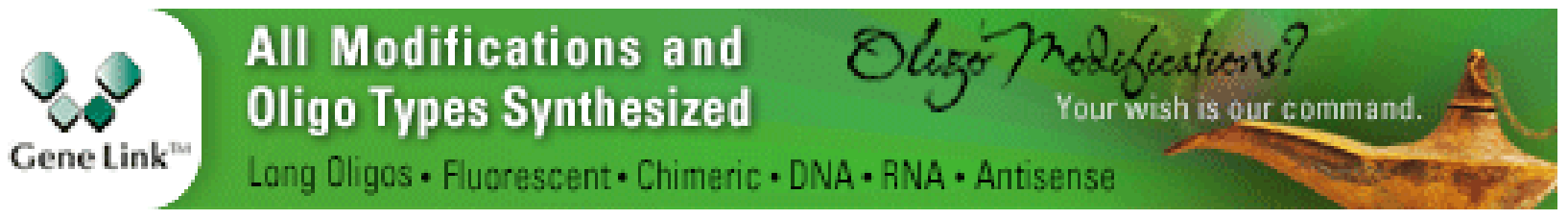


For additional articles in this collection, see http://cshperspectives.cshlp.org/cgi/collection/

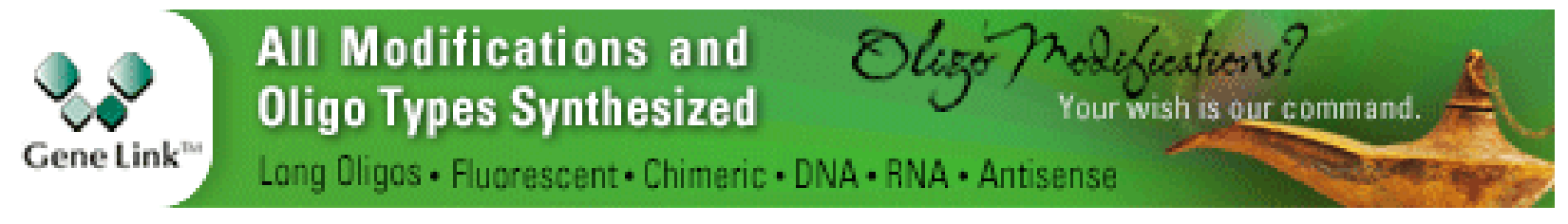

Copyright @ 2016 Cold Spring Harbor Laboratory Press; all rights reserved 